bioRxiv preprint first posted online Nov. 4, 2018; doi: http://dx.doi.org/10.1101/460469. The copyright holder for this preprint (which was not peer-reviewed) is the author/funder, who has granted bioRxiv a license to display the preprint in perpetuity.

It is made available under a CC-BY-NC 4.0 International license.

\title{
AUTOMAGIC: Standardized Preprocessing of Big EEG Data
}

\author{
Andreas Pedroni ${ }^{1 *}$, Amirreza Bahreini ${ }^{1}$, Nicolas Langer ${ }^{1 *}$ \\ Methods for Plasticity Research, Psychological Institute, University of Zurich \\ *corresponding authors
}

Andreas Pedroni: anpedroni@gmail.com

Nicolas Langer: n.langer@psychologie.uzh.ch

Address: Psychologisches Institut

Methoden der Plastizitätsforschung

Andreasstrasse 15, AND 4.58

CH-8050 Zürich, Switzerland 
bioRxiv preprint first posted online Nov. 4, 2018; doi: http://dx.doi.org/10.1101/460469. The copyright holder for this preprint (which

was not peer-reviewed) is the author/funder, who has granted bioRxiv a license to display the preprint in perpetuity.

It is made available under a CC-BY-NC 4.0 International license.

\title{
AUTOMAGIC
}

\begin{abstract}
Electroencephalography (EEG) recordings have been rarely included in large-scale studies. This is arguably not due to a lack of information that lies in EEG recordings but mainly on account of methodological issues. In many cases, particularly in clinical, pediatric and aging populations, the EEG has a high degree of artifact contamination and the quality of EEG recordings often substantially differs between subjects. Although there exist a variety of standardized preprocessing methods to clean EEG from artifacts, currently there is no method to objectively quantify the quality of preprocessed EEG. This makes the commonly accepted procedure of excluding subjects from analyses due to exceeding contamination of artifacts highly subjective. As a consequence, P-hacking is fostered, the replicability of results is decreased, and it is difficult to pool data from different study sites. In addition, in large-scale studies, data are collected over years or even decades, requiring software that controls and manages the preprocessing of ongoing and dynamically growing studies. To address these challenges, we developed AUTOMAGIC, an open-source MATLAB toolbox that acts as wrapper to run currently available preprocessing methods and offers objective standardized quality assessment for growing studies. The software is compatible with the Brain Imaging Data Structure (BIDS) standard and hence facilitates data sharing. In the present paper we outline the functionality of AUTOMAGIC and examine the effect of applying combinations of methods on a sample of resting EEG data. This examination suggests that a applying a pipeline of algorithms to detect artifactual channels in combination with Multiple Artifact Rejection Algorithm (MARA), an independent component analysis (ICA)-based artifact correction method, is sufficient to reduce a large extent of artifacts.
\end{abstract}

Keywords: EEG, artifacts, preprocessing, quality control, BIDS 
bioRxiv preprint first posted online Nov. 4, 2018; doi: http://dx.doi.org/10.1101/460469. The copyright holder for this preprint (which

was not peer-reviewed) is the author/funder, who has granted bioRxiv a license to display the preprint in perpetuity.

It is made available under a CC-BY-NC 4.0 International license.

\section{AUTOMAGIC}

\section{Introduction}

Major breakthroughs in translating insights from research in neuroscience to diagnose or treat mental disorders have been rare (Kapur et al., 2012). To foster advances, several suggestions have been made to change paradigms and practices in research. This includes reconceptualizing the definition of mental disorders with concepts that are closer to their biological underpinnings and searching for diagnostic markers at this level (Cuthbert and Insel, 2013). Furthermore, it has been suggested to move away from studying disorders in isolation and rather investigate disorders in the natural co-occurence of multiple disorders. At last, it is proposed that study samples should cover a heterogeneous composition of symptoms in various degrees of severity, facilitating the generalization and application of results to broader populations (Woo et al., 2017).

To implement these suggestions, studies with vast sample sizes are needed. This has become manifest in an increasing number of large-scale research initiatives (Eickhoff et al., 2016), such as the IMAGEN study (Schumann et al., 2010), the UK Biobank (Sudlow et al., 2015), the Autism Brain Imaging Data Exchange (Di Martino et al., 2014) or the Alzheimer's Disease Neuroimaging Initiative (ADNI) (Mueller et al., 2005). These biomarker initiatives have assessed various sets of neuropsychological, lifestyle phenotypes and brain-imaging measures, predominantly using structural and functional magnetic resonance imaging ( $\mathrm{s} / \mathrm{fMRI})$. One aspect, which is at first sight surprising, is that with the exception of one notable initiative, the Healthy Brain Network study (Alexander et al., 2017; Langer et al., 2017a), electroencephalography (EEG) measures have not been included in any large biomarker initiative.

We believe that the current paucity of EEG measures in large-scale biomarker studies is not due to a lack of information about neuronal processes that can be gained from EEG. Complementing the 
bioRxiv preprint first posted online Nov. 4, 2018; doi: http://dx.doi.org/10.1101/460469. The copyright holder for this preprint (which was not peer-reviewed) is the author/funder, who has granted bioRxiv a license to display the preprint in perpetuity.

It is made available under a CC-BY-NC 4.0 International license.

\section{AUTOMAGIC}

rather static view of the brain that is offered by MRI with information at the speed of the actual brain processes, a wealth of studies has shown that the EEG in various mental disorders deviates from healthy controls. EEG recorded during rest is highly reliable (Lund et al., 1995; Näpflin et al., 2007) and is altered in various mental diseases, such as ADHD (Boutros et al., 2005), autism spectrum disorders (Wang et al., 2013), schizophrenia (Boutros et al., 2008), depression and anxiety disorders (Thibodeau et al., 2006), and dementia and mild cognitive impairment (Jelic and Kowalski, 2009). There are also abundant studies showing that task-related EEG parameters differ between healthy controls and patients suffering from various disorders (Cecchi et al., 2015; Duncan et al., 2009; Pfefferbaum et al., 1984). Furthermore, specific event-related potentials are suggested to reflect endophenotypes, for instance for anxiety disorders, depression, and substance abuse (Olvet and Hajcak, 2008). Task-related EEG additionally offers insights into the processing steps that are required to perform tasks, thus allowing insights into why a person performs more or less well in a cognitive task (Langer et al., 2017b). This reflects an aspect, which complements neuropsychological testing (often included in biomarker studies), that typically only provides information about performance in the form of a single score. Finally, EEG measures also favorable from an economic point of view: If EEG-based biomarkers are identified, the financial burden of implementing widespread screening for such markers is low compared to MRI-based screening.

One major challenge that has hindered the large-scale application of EEG is the difficulty of obtaining EEG recordings that are comparable in their quality between subjects. The EEG signal is influenced by technical factors and by characteristics of the recorded subject. For instance, the EEG signal is influenced by environmental factors such as temperature and air humidity and these factors interact with sources of noise, such as line noise, or other sources of electromagnetic noise (Kappenman and Luck, 2010). In addition, subject-related artifacts, typically reflecting unwanted 
bioRxiv preprint first posted online Nov. 4, 2018; doi: http://dx.doi.org/10.1101/460469. The copyright holder for this preprint (which was not peer-reviewed) is the author/funder, who has granted bioRxiv a license to display the preprint in perpetuity.

It is made available under a CC-BY-NC 4.0 International license.

\section{AUTOMAGIC}

physiological signals (such as eye movements, eye blinks, muscular noise, heart signals and sweating), may differ from subject to subject and may interact in a complex manner with non-physiological artifacts. The resulting artifact signals in the EEG are typically more prominent than the signal of interest (i.e. brain activity) and hence require preprocessing in the form of artifact cleaning or artifact correction (Keil et al., 2014).

Various automated artifact preprocessing pipelines have been developed to preprocess EEG data. They apply methods of source separation techniques (Delorme et al., 2007; Gabard-Durnam et al., 2018; Jung et al., 2000), regression methods, and linear decomposition (Parra et al., 2005) to clean EEG data. In addition, there exist various methods of detecting and removing artifactual channels and segments from EEG (Chaumon et al., 2015; Hatz et al., 2015; Mognon et al., 2011; Nolan et al., 2010; Winkler et al., 2011). A number of processing pipelines combine parts of these methods and/or extend them. For example, the PREP pipeline (Bigdely-Shamlo et al., 2015) offers standardized early-stage EEG processing, includes sophisticated methods to remove line-noise (using Clean Line, (Mullen, 2012) and robust average referencing by iteratively detecting and interpolating artifactual channels. The Harvard Automated Processing Pipeline for EEG (HAPPE) (Gabard-Durnam et al., 2018) and the automatic pre-processing pipeline (APP) for EEG analysis (da Cruz et al., 2018) combine multiple methods into pipelines that additionally offer artifact correction using independent component analysis (ICA) and Multiple Artifact Rejection Algorithm (MARA, (Winkler et al., 2011)). The Computational Testing for Automated Preprocessing (CTAP) toolbox (Cowley et al., 2017; Cowley and Korpela, 2018) has a similar goal but additionally offers functions to optimize the different preprocessing methods by allowing the user to compare different pipelines. The Batch Electroencephalography Automated Processing Platform (BEAPP, (Levin et al., 2018) ) reflects a platform for batch processing 
bioRxiv preprint first posted online Nov. 4, 2018; doi: http://dx.doi.org/10.1101/460469. The copyright holder for this preprint (which was not peer-reviewed) is the author/funder, who has granted bioRxiv a license to display the preprint in perpetuity.

It is made available under a CC-BY-NC 4.0 International license.

\section{AUTOMAGIC}

of EEG that allows the creation of preprocessing pipelines with a variety of options that can be re-applied to new datasets, hence facilitating the exact methodological replication of studies.

Although all of these preprocessing pipelines do a remarkably good job in removing artifacts from EEG, arguably none of them would claim to be able to do this perfectly. Therefore, the extent to which a subject produces artifacts, such as moving the eyes or blinking, not only influences the signal in the raw EEG but may leave spurious traces in the preprocessed EEG. As a consequence, preprocessed EEG may vary to large extent between subjects. In some cases where the EEG signal is highly contaminated with noise, which is often the case in heterogeneous study populations such as developmental studies with children and elderly subjects or in clinical studies, artifact correction cannot recover the EEG signal from the noise in a satisfactory way. It is then often unavoidable common practice to dismiss a selection of EEG recordings due to inferior quality from the analyses that enter a study.

The decision of whether a recording has acceptable quality to be submitted to further analysis is highly subjective and depends on many factors such as the recording length (i.e. number of trials), sample size, the effect sizes of interest and, foremost, the specific research question. In studies with small sample sizes it is manageable for one researcher to perform this classification, which is typically based on the visual inspection of the preprocessed $\mathrm{EEG}^{1}$. Even in the case that one person assesses an entire dataset, the classification within the dataset might vary as a function of his/her motivation, tiredness and on the previously reviewed datasets. Moreover, it can be highly problematic if the data are not blinded and are classified with knowledge about the hypotheses. Things may become more intricate in large-scale studies with thousands of datasets, where it is not feasible for one person to

\footnotetext{
${ }^{1}$ The visual classification of EEG has been shown to be moderately reliable (kappa $\left.=0.75\right)$ and can be improved with training (kappa $=0.91)$ (Hatz et al., 2015).
} 
bioRxiv preprint first posted online Nov. 4, 2018; doi: http://dx.doi.org/10.1101/460469. The copyright holder for this preprint (which

\section{AUTOMAGIC}

classify all data sets and the classification sensitivity may change from researcher to researcher, and thus may introduce biases in the study sample that lower the generalizability of results.

Recently, the HAPPE (Gabard-Durnam et al., 2018) processing pipeline has been introduced; it offers standardized metrics of the data quality, allowing objective classification of datasets. Quality metrics are the number of interpolated channels, the number of epochs that survive epoch-wise artifact rejection after preprocessing, the number of independent components (IC) that are rejected as artifact components and the retained variance of the EEG data after IC rejection. Although these metrics are helpful to assess the quality of data, they rely on how well the preprocessing was able to identify artifacts. For instance, the percentage of interpolated channels (i.e. channels that are contaminated by artifacts) depends on how well a bad-channel detection algorithm is capable to detect noisy channels. Since the noise may vary between subjects, the bad-channel detection algorithm may vary in the sensitivity to identify a noisy channel. In addition the retained variance of the EEG data after IC rejection is influenced by how clean the data are when entering the ICA. More retained variance does not per se indicate less noisy data. Therefore, the quality metrics are only valid if the preprocessing is equally capable of identifying artifacts in each recording, an assumption on which our experience casts doubt. We propose additional quantitative quality metrics that are not dependent on the identification of artifacts or bad channels on which to base inclusion/exclusion criteria for EEG recordings in a more standardized way.

A further practical problem that hinders the implementation of EEG measurements in large-scale studies is a lack of software that allows the handling of large and, in particular, growing datasets. Large-scale studies and longitudinal studies typically run over many years and it is impractical to hold back data preprocessing until the end of a study. Often, research questions can be addressed in $a$ priori defined subsamples of a large study and therefore scientific progress would be slowed if data are 
bioRxiv preprint first posted online Nov. 4, 2018; doi: http://dx.doi.org/10.1101/460469. The copyright holder for this preprint (which was not peer-reviewed) is the author/funder, who has granted bioRxiv a license to display the preprint in perpetuity.

It is made available under a CC-BY-NC 4.0 International license.

\section{AUTOMAGIC}

not released until the endpoint of a study. This requires that preprocessing software is capable of handling growing studies by keeping track of the already preprocessed datasets and by freezing preprocessing settings (and software versions) to assure a standardized procedure. To the best of our knowledge no such software solution exists so far in the realm of EEG.

In addition to the urge of standardizing preprocessing, there is a need for a principled format to organize, harmonize, and share data. In the recent years, EEG datasets have been made increasingly openly available (for a list of shared EEG datasets, see https://github.com/voytekresearch/OpenData) and it has been shown that integrating EEG datasets across studies offers unique insights unavailable in single studies (Bigdely-Shamlo et al., 2018a, 2018b). The principled way of data sharing has been successfully adopted in the domain of MRI data with the introduction of the Brain Imaging Data Structure (BIDS), the emerging standard for the organisation of neuroimaging data (Gorgolewski et al., 2016). Various extensions of the BIDS format (including extensions for EEG data (Pernet et al., 2018a)) have been proposed (https://bids.neuroimaging.io) that not only provide a standard for the respective data modality but moreover facilitate the integration between data of different modalities (e.g. simultaneous fMRI and EEG recordings). To make EEG data sharing simple and intuitive, it would therefore be beneficial if a preprocessing pipeline supports BIDS format as in- and output. In the present paper we aim to narrow the current gaps in EEG preprocessing that hamper large-scale studies and open science practices, by presenting a software solution that implements a selection of currently available artifact correction procedures in addition to a novel quality assessment tool that relies on standardized and quantitative quality metrics that are independent from the preprocessing. In addition, the software handles growing studies, supports the BIDS format and hence facilitates data sharing. To foster scientific transparency and make exact methodological replications of studies easier, detailed information of all processing steps are stored in a log-file in accordance to 
bioRxiv preprint first posted online Nov. 4, 2018; doi: http://dx.doi.org/10.1101/460469. The copyright holder for this preprint (which was not peer-reviewed) is the author/funder, who has granted bioRxiv a license to display the preprint in perpetuity.

It is made available under a CC-BY-NC 4.0 International license.

\section{AUTOMAGIC}

(Pernet et al., 2018b) and project settings of already existing studies can be saved and imported. The software, called AUTOMAGIC, is based on Matlab, open source and freely available under the terms of the GNU General Public License. It is available from https://github.com/methlabUZH.

\section{The AUTOMAGIC processing pipeline for big EEG data}

\subsection{Overview}

AUTOMAGIC has been developed with the intention of offering a user-friendly preprocessing software for big (and small) EEG datasets. One major focus of the software lies in the standardization of the preprocessing and quality control and the transparent and standardized reporting to facilitate open science practices. The software can be fully run by command line or with a graphical user interface (GUI) and therefore does not require any knowledge of programming. It runs with MATLAB (from Version 2016b) and can be installed with a few clicks. Due to the fact that AUTOMAGIC is compiled of several MATLAB functions that are compatible with EEGLAB (Delorme and Makeig, 2004), one of the most used open-source frameworks for EEG analysis), more experienced users can readily modify AUTOMAGIC to their specific needs. In addition, AUTOMAGIC can be used as an EEGLAB extension.

AUTOMAGIC contains three basic sections, the project section, the configuration section, and the quality assessment section. A typical workflow involves the following steps: In the project section, the user defines the input and output folders of the processing and information about the EEG data, such as the format, channel locations, and electrooculogram (EOG)-channels. The configuration section allows the selection of various preprocessing steps with their settings that are applied to the EEG. After preprocessing of the data and the interpolation of bad channels, the user can review the quality of the 


\section{AUTOMAGIC}

preprocessing in the quality section. Here, EEG datasets can be displayed as heatmaps (with dimensions of channels and time) or classical EEG channel plots (using the eegplot function of EEGLAB), allowing the user to obtain a comprehensive overview of the data quality. In addition, various quality criteria are computed such as the ratio time windows of high voltage amplitudes. Finally, the user can define cutoffs for these quality criteria to objectively include datasets of good quality and exclude datasets of too poor quality. For each dataset, the exact sequence of the preprocessing steps are stored in a log-file and all the parameters of the preprocessing and the quality measures are stored in a MATLAB structure and in a json-File that is stored along the preprocessed data. The entire project can be exported to BIDS format, which includes a raw data folder (with the raw data), a derivative folder with the preprocessed data and the code that translates raw to derivative. In the following sections, we will walk through the processing steps (see Figure 1 for an overview) of AUTOMAGIC and provide detailed information. 
bioRxiv preprint first posted online Nov. 4, 2018; doi: http://dx.doi.org/10.1101/460469. The copyright holder for this preprint (which

was not peer-reviewed) is the author/funder, who has granted bioRxiv a license to display the preprint in perpetuity.

It is made available under a CC-BY-NC 4.0 International license.

\section{AUTOMAGIC}

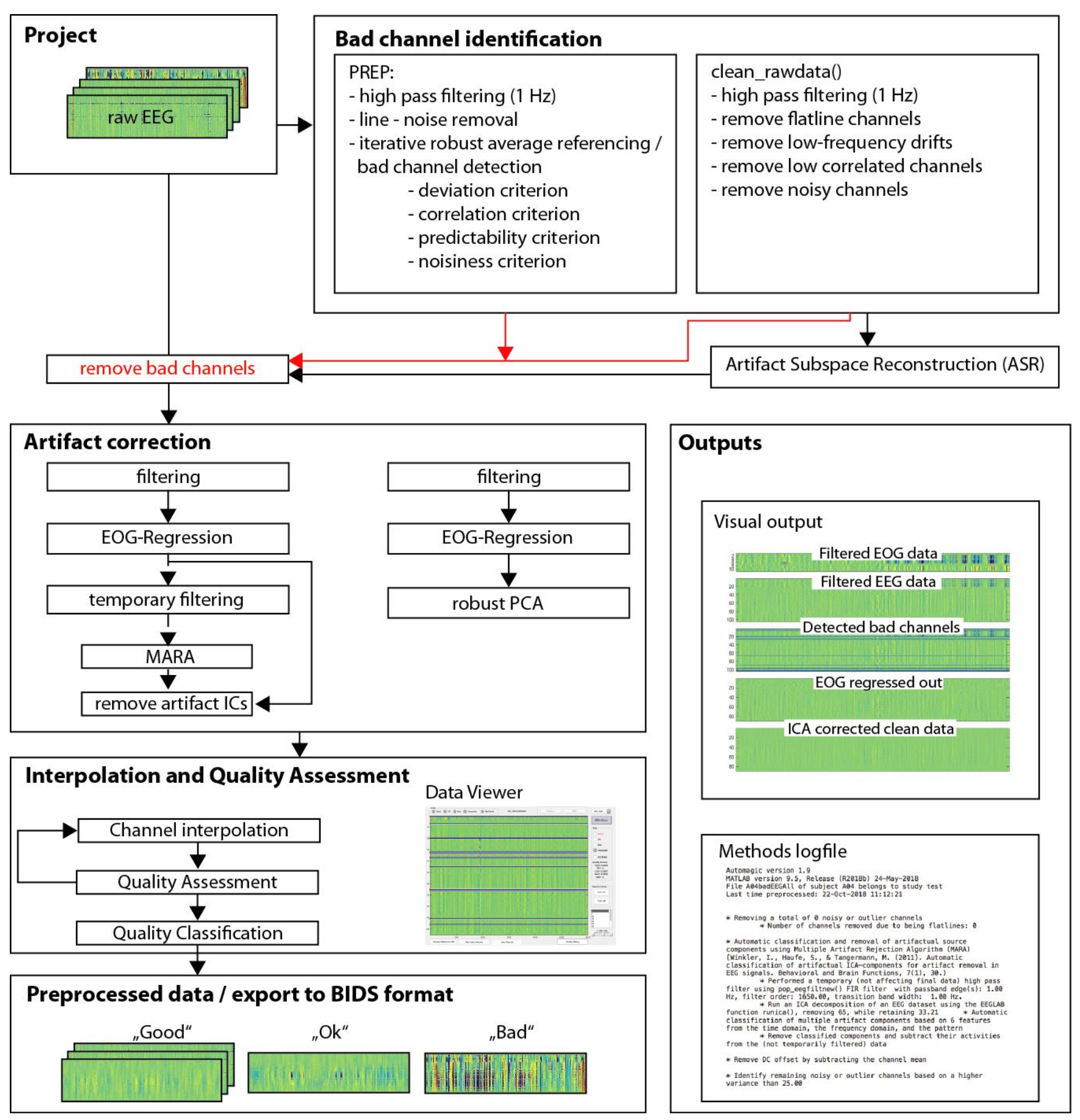

Figure 1. Typical workflow of AUTOMAGIC. The raw EEG data are organized in a project. Each dataset within a project enters the bad channel identification routines chosen by the user, detecting noisy, flat or outlier channels. These channels (red arrow) are subsequently removed from the original EEG. When choosing Artifact Subspace Reconstruction (ASR), the EEG is additionally corrected for corrupt segments at this point. In a next step, the EEG can be filtered and the user can choose to apply the artifact correction methods of EOG-regression and MARA or rPCA. In a next step, the bad channels are interpolated and the quality of each dataset is assessed using a number of objective criteria. Finally, the user can categorize the quality of each dataset into "Good", "OK" and "Bad", by applying cutoffs to the quality criteria. In addition, a visual summary of the preprocessing for each dataset and a log-file with the applied methods are saved. 
bioRxiv preprint first posted online Nov. 4, 2018; doi: http://dx.doi.org/10.1101/460469. The copyright holder for this preprint (which

was not peer-reviewed) is the author/funder, who has granted bioRxiv a license to display the preprint in perpetuity.

It is made available under a CC-BY-NC 4.0 International license.

\section{AUTOMAGIC}

\subsubsection{Project}

The basic idea behind a project is that the user defines a data folder, which is the source of preprocessing, along with a results folder, which is the target for the preprocessed data, additional output files and a list of configurations for the preprocessing, which is stored in the results folder in a so-called project file (project_state.mat). Once the configurations have been defined and a project has been created, all the configurations are fixed and can no longer be changed, thus assuring that all datasets are processed in an identical fashion. In contrast to having the configurations fixed, the input files are not; hence, it is always possible to add (or to delete) datasets to a data folder and AUTOMAGIC detects these changes whenever the application is restarted. This guarantees that all EEG files are preprocessed in a standardized way.

\subsubsection{EEG data import}

AUTOMAGIC supports most common EEG file types, specifically all the EEG file types that can be imported with EEGLAB (see https://sccn.ucsd.edu/wiki/EEGLAB Extensions_and plug-ins). In addition, the EGI HCGSN "raw." file format is supported for 128 and 256 (or 129 and 257 if reference electrode is included respectively), with included channel locations.

\subsection{Bad channel identification}

In a first step, so-called "bad channels" are identified ${ }^{2}$. Generally, bad channels are those with low recording signal-to-noise ratio (SNR) or very low or no signal throughout a considerable span of

\footnotetext{
${ }^{2}$ Note that it is possible to skip bad channel identification, but it is advisable to identify and later exclude bad channels before applying artifact correction routines because methods such as the ICA applied in MARA or the rPCA may not work properly if bad channels are not excluded beforehand.
} 
bioRxiv preprint first posted online Nov. 4, 2018; doi: http://dx.doi.org/10.1101/460469. The copyright holder for this preprint (which was not peer-reviewed) is the author/funder, who has granted bioRxiv a license to display the preprint in perpetuity.

It is made available under a CC-BY-NC 4.0 International license.

\section{AUTOMAGIC}

time of the EEG recording. If there are only few channels affected by such noise/low signal it is impractical to reject/correct entire time windows of the EEG for this reason. Instead, it in many cases is more sensible to interpolate the signal of bad channels by the combined signal of channels with adequate SNR or to discard bad channels for further analyses.

AUTOMAGIC creates a copy from the original raw EEG data, which is submitted to algorithms whose purpose is to detect bad channels. In this way, the original data are unaffected by the high-pass filtering with a cutoff of $1 \mathrm{~Hz}$ that is performed by default for the currently supported bad channel removal algorithms. Note that the bad channel identification procedures only detect bad channels and do not modify (e.g. interpolate channels) the EEG data. Bad channels are interpolated after the preprocessing.

\subsubsection{Bad channel identification and robust average referencing using the PREP pipeline}

By default, AUTOMAGIC uses the PREP pipeline (Bigdely-Shamlo et al., 2015) that offers four sophisticated bad channel identification algorithms and a method to estimate a robust average reference. The specific processing steps are described in detail in (Bigdely-Shamlo et al., 2015) and on http://vislab.github.io/EEG-Clean-Tools/. Here, we only outline the key steps. In a first step, the copy of the original EEG data are high-pass filtered with a cutoff of $1 \mathrm{~Hz}$. Next, power line noise is removed, using the "cleanLine" EEGLAB plugin developed by Mullen (2012), which estimates the amplitude and size of a deterministic sinusoid at a specified frequency embedded in locally white noise. The algorithm requires approximate indications of the frequencies to be removed, which are by default multiples from the frequency of the line power filter input, up to half of the Nyquist frequency.

After these two initial steps, PREP iteratively estimates a robust average reference. The robust average reference method subtracts the average of all "good" (i.e. not "bad") channels from each 
bioRxiv preprint first posted online Nov. 4, 2018; doi: http://dx.doi.org/10.1101/460469. The copyright holder for this preprint (which was not peer-reviewed) is the author/funder, who has granted bioRxiv a license to display the preprint in perpetuity.

It is made available under a CC-BY-NC 4.0 International license.

\section{AUTOMAGIC}

channel. Specifically, the algorithm iteratively detects and interpolates bad channels to arrive at an average reference that is not affected by artifacts. It uses four measures for this: extreme amplitudes (deviation criterion), lack of correlation with any other channel (correlation criterion), lack of predictability by other channels (predictability criterion), and unusual high frequency noise (noisiness criterion). Note that the estimated robust average reference is only computed but not applied to the EEG data. Therefore, the data remain referenced to the initial reference. Note that the PREP pipeline is quite computationally expensive, especially on datasets with many EEG channels, and it is advisable to allow PREP using the parallel processing offered by MATLAB, which is done by default.

\subsubsection{Bad channel identification using clean_rawdata()}

A computationally less expensive and faster alternative (or an addition) to the bad channel identification algorithms offered by PREP, are the three bad channel identification algorithms of the EEGLAB plugin clean_rawdata() (http://sccn.ucsd.edu/wiki/Plugin_list_process). The first algorithm detects channels that have no signal variation for a duration of longer than $5 \mathrm{~s}$. The EEG of the remaining channels is then filtered with a forward-backward (non-causal) filter (with transition band of $0.5-1 \mathrm{~Hz}$ and stop-band attenuation of $80 \mathrm{db}$ ) to remove slow-wave drifts. The second algorithm (equivalent to the predictability criterion of PREP) searches for channels with a lower correlation to its robust estimate (based on other channels) than a given threshold. Specifically, (using the default settings) it calculates the correlation of each channel in a time window of $5 \mathrm{~s}$ of the EEG to its random sample consensus (RANSAC) reconstruction (with 50 samples derived from a subset of $25 \%$ of all channels). If the correlation is below 0.85 in more than $40 \%$ of times, the respective channel is identified as bad. The third algorithm removes EEG channels with excessive line noise. It extracts the signal above $50 \mathrm{~Hz}$ from the raw EEG, which is considered line noise. Then the median absolute 
bioRxiv preprint first posted online Nov. 4, 2018; doi: http://dx.doi.org/10.1101/460469. The copyright holder for this preprint (which

was not peer-reviewed) is the author/funder, who has granted bioRxiv a license to display the preprint in perpetuity.

It is made available under a CC-BY-NC 4.0 International license.

\section{AUTOMAGIC}

deviation (MAD) of the difference between raw EEG and the line noise is calculated and divided by the MAD of the line noise, which gives a relative noise-to-signal estimate for each channel. This estimate is z-transformed and channels with a z-value above 4 (i.e. 4 standard deviations above the channel population mean) are marked as bad channels. ${ }^{3}$

In addition to the bad channel identification algorithms, clean_rawdata() offers a function that automatically detects and repairs artifacts using the Artifact Subspace Reconstruction (ASR) method (Mullen et al., 2013). This method does not identify bad channels, but detects "bad" time windows (with pronounced bursts of noise) in the data and attempts to interpolate this data based on the rest of the EEG signal during these time periods. A second function identifies and removes time periods that could not be recovered by ASR (with abnormally high power from the data). Note that the selection of these two additional processing steps has consequences for the original EEG as the EEG dataset might be shortened by the time periods that could not be adequately recovered. In a limited set of tests with small data sets, we observed that the time periods rejected by ASR varied and hence were not perfectly replicable. Therefore, we suggest testing the use of ASR with respective data sets.

\subsubsection{Residual bad channel detection}

In addition to these algorithms, we found it for some datasets helpful to identify channels that show exceedingly high variance over time. Bad channels are identified by searching for channels with a standard deviation exceeding a certain threshold (by default $25 \mathrm{mV}$ ). Note that this residual channel identification algorithm is applied after the entire preprocessing. The reason for applying this step after preprocessing is to identify whether residual noisy channels also remain after the artifact correction, which we have observed in some cases.

\footnotetext{
${ }^{3}$ Note that changing the default settings of clean_rawdata() needs to be done in the respective functions.
} 


\section{AUTOMAGIC}

\subsubsection{Bad channel removal}

After having run either (or both) of the bad channel identification pipelines (clean_rawdata() and/or the PREP pipeline) the selection of identified bad channels is excluded from the original EEG data (see Fig. 1). This is done because, for instance, the ICA used in a later processing step in many cases does not work with bad channels (e.g. flat channels). Note that from this point on, the downstream processing changes the EEG signals but thus far no channels are interpolated.

\subsection{Filtering}

In this step, EEG data can be filtered using low-pass, high-pass and or notch-filter, implemented in EEGLAB's pop_eegfiltnew().

\subsection{Artifact correction}

Although bad channel identification methods have the goal of identifying a distinct set of channels with low SNR throughout a considerable span of time of the EEG recording, many artifacts span multiple channels, while being more temporally isolated, such as eye-blinks and movement muscle artifacts. One simple approach to handle such artifacts is to detect them (e.g. EOG data with amplitudes $\pm 75 \mathrm{~V}$ ) and delete these time segments. However, this can potentially lead to a large loss of data, consequently reducing the SNR and the quality of downstream analyses (i.e. too few trials for an ERP). To avoid loss of data, various methods exist that remove the artifacts while preserving the underlying neural activity. In AUTOMAGIC three such artifact correction methods are implemented, 
bioRxiv preprint first posted online Nov. 4, 2018; doi: http://dx.doi.org/10.1101/460469. The copyright holder for this preprint (which

was not peer-reviewed) is the author/funder, who has granted bioRxiv a license to display the preprint in perpetuity.

It is made available under a CC-BY-NC 4.0 International license.

\section{AUTOMAGIC}

with the EOG regression, MARA, an ICA-based correction method, and a robust principal component analysis (rPCA) method.

\subsubsection{EOG regression (EOGr)}

In this step, artifacts that are caused by eye movements are separated from the EEG signal, using the subtraction method that relies on linear transformation of the EEG activity (see (Parra et al., 2005). This method is similar to the classical regression approach, where EOG electrodes are used as a reference signal that is subtracted in proportion to their contribution to each EEG channel (Croft and Barry, 2000). The main difference to the classical approach is that EEG channels are also used to construct an optimal estimate of the EOG activity as reference for subtraction.

\subsubsection{Multiple Artifact Rejection Algorithm (MARA)}

The Multiple Artifact Rejection Algorithm (MARA) (Winkler et al., 2014, 2011), used as a default, is an open-source EEGLAB plug-in which automatizes the process of hand-labeling independent components (ICs) for artifact rejection. In short, ICs of the EEG are separated by independent component analysis (ICA) using the runica() algorithm implemented in EEGLAB. MARA classifies ICs into ones that reflect artifacts and those that reflect EEG. This classification is based on a supervised learning algorithm that has learned from expert ratings of 1290 components considering six features from the spatial, the spectral and the temporal domain. The ICs that are classified as artifacts are removed and their activities are subtracted from the data. Note that prior to the ICA, a copy of the data is made and high-pass filtered with a cutoff of $1 \mathrm{~Hz}$. This is done because the ICs classified as artifacts are removed from the original data, allowing the data to be filtered with lower cutoff frequencies than those optimal for running the ICA in MARA. 


\section{AUTOMAGIC}

\subsubsection{Noise removal using robust PCA (rPCA)}

An alternative (and faster) way of removing artifacts is the use of robust principal component analysis (rPCA). The implemented algorithm (Lin et al., 2010) estimates a low-dimensional subspace of the observed data, reflecting the signal that is cleaned from sparse corruptions. In contrast to the classical PCA, the rPCA is able to efficiently estimate true low-dimensional subspace even when the observations are grossly corrupted. We advise using the ICA instead of the rPCA, as previously suggested by Jung and colleagues (2000) because we have observed that in some cases oscillatory signals that are for example induced in steady state visual evoked potential (SSVEP) paradigms are removed by the rPCA.

\subsection{DC offset removal}

As a final preprocessing step, the DC offset is removed by subtracting the channel-wise mean from each data point.

\subsection{Preprocessed data and auxiliary outputs}

The preprocessed datasets are saved sequentially. ${ }^{4}$ Therefore, the user can interrupt and continue the preprocessing at any time without losing preprocessed data. AUTOMAGIC saves preprocessed data as a MATLAB MAT-file (Version 7.3). After preprocessing the prefix " $p$ " (for preprocessed) is added to the filename. The MAT-file contains two structures, a structure named $E E G$ that corresponds to the EEG structure of EEGLAB (see EEGLAB https://sccn.ucsd.edu/wiki/A05:_Data_Structures) and a

\footnotetext{
${ }^{4}$ Note that the data, which is the input to preprocessing, are not modified at any time.
} 
bioRxiv preprint first posted online Nov. 4, 2018; doi: http://dx.doi.org/10.1101/460469. The copyright holder for this preprint (which

was not peer-reviewed) is the author/funder, who has granted bioRxiv a license to display the preprint in perpetuity.

It is made available under a CC-BY-NC 4.0 International license.

\section{AUTOMAGIC}

structure named automagic. Saving the preprocessed data in an EEGLAB EEG structure makes it possible to readily use EEGLAB for further analyses by simply loading the MAT-files to MATLAB

workspace. ${ }^{5}$ The automagic structure contains all parameters of the preprocessing and quality

measures. The two structures $E E G$ and automagic can be selectively loaded (using

load(filename,structure)), which saves time when loading data, for instance if one wants to inspect the information in the (small in byte-size) automagic structure.

For each preprocessed dataset, a jpg. file is saved (in the same folder), providing a visual representation of the effects of the applied preprocessing methods. ${ }^{6}$ In addition, a log-file is saved for each dataset, describing the exact order and the used parameters of the preprocessing steps. This logfile can be used to precisely communicate the preprocessing of an EEG project in a publication in accordance with the recommendation for reporting standards of the Committee on Best Practice in Data Analysis and Sharing (COBIDAS) (Pernet et al., 2018b).

\subsection{Data Viewer}

The user can now review the data in the Data Viewer, where each dataset is plotted as a heatmap and bad channels are marked with blue lines allowing the user to obtain a comprehensive overview of the data quality. The preprocessed datasets can be furthermore visually compared to the raw $1 \mathrm{~Hz}$ high-pass filtered data. Furthermore, it is possible to manually select bad channels that have not been detected by the applied methods; however, for the sake of replicability we discourage this.

\footnotetext{
${ }^{5}$ EEGLAB functions can be directly applied to the loaded EEG structure. Alternatively, by starting EEGLAB and calling the command eeglab -redraw the EEG structure in MATLAB's workspace becomes accessible in the EEGLAB GUI.

${ }^{6}$ Users may have observed a reduced_*.mat file in the results folders. This file is a downsampled version of the EEG data and is used for faster displaying in the data viewer.
} 


\section{AUTOMAGIC}

\subsection{Bad channel interpolation}

In a next step all the channels that have been detected as bad channels can be interpolated using the eeg_interp() function of EEGLAB with the "spherical" interpolation method as a default. After interpolation the EEG data are saved and the prefix "i" (for interpolated) is added to the filename.

\subsection{Quality assessment}

The goal of the quality assessment module is to provide objective measures of the data quality after preprocessing. Because datasets in a project may be differently contaminated by artifacts, more or less channels may have been detected and interpolated. Similarly, the artifact correction methods may have been more or less effective in cleaning the data from artifacts. This can lead to variability in data quality within a project and often requires the researcher to exclude overly contaminated datasets from downstream analyses. Obviously, the decision about which datasets to exclude from an analysis leaves many degrees of freedom and hence may lead to an increase in Type I errors (Simmons et al., 2011) in the statistical inference of downstream analyses. Automagic offers a number of objective quality measures with which datasets can be compared within a project and objective exclusion criteria can be determined. These criteria can be used to facilitate the exact replication of a project or can be included in the pre-registration of an entire methodological workflow in an EEG analysis.

\subsubsection{Quality measures}

Ratio of Bad Channels (RBC). One indicator of the quality of the data is the ratio of identified bad and consequently interpolated channels (RBC). The more channels that are interpolated the more 
bioRxiv preprint first posted online Nov. 4, 2018; doi: http://dx.doi.org/10.1101/460469. The copyright holder for this preprint (which

was not peer-reviewed) is the author/funder, who has granted bioRxiv a license to display the preprint in perpetuity.

It is made available under a CC-BY-NC 4.0 International license.

\section{AUTOMAGIC}

of the signal of interest is lost, hence the worse the data quality. To assess the extent of signal loss is not straightforward because the signal loss depends on the spatial configuration of interpolated channels. If many bad channels are located in clusters the signal loss is greater than bad channels that are spatially scattered across the scalp. Therefore, this quality measure should be considered together with the scalp distribution of interpolated channels and clustered bad channels should be considered as more negatively affecting the quality of the data than scattered bad channels.

The quality of each dataset is furthermore assessed using three types of quality measures that are based on the magnitude of the voltage amplitudes. A range of thresholds can be defined for these measures, resulting in quality measures of different sensitivity.

Ratio of data with overall high amplitude (OHA). The quality measure of the overall high amplitude (OHA) is defined by calculating the ratio of data points (i.e. channels $c \mathrm{x}$ timepoints $t$ ) that have a higher absolute voltage magnitude $v$ of $x \mathrm{mV}$,

$$
O H A(x)=\frac{1}{N} \sum_{c t}^{N} v_{c t}>|x|
$$

where $x$ reflects a vector of voltage magnitude thresholds (e.g. $x=10 \mathrm{mV}, 20 \mathrm{mV}, 30 \mathrm{mV}, 50 \mathrm{mV}, 60$ $\mathrm{mV}, 70 \mathrm{mV})$ and $N$ reflects the number of data points. Thus, each $\mathrm{OHA}(x)$ threshold results in a quality measure that differs in its sensitivity.

Ratio of timepoints of high variance (THV). Similarly, the ratio of time points $t$ is identified, where the standard deviation $\sigma$ of the voltage measures $v$ across all channels $c$ exceeds $x \mathrm{mV}$, where $x$ reflects a vector of standard deviation thresholds and $T$ the number of time points. The ratio of timepoints that exceeds such a threshold reflects the timepoints of high variance (THV) criterion for a given threshold $x$ :

$$
T H V(x)=\frac{1}{T} \sum_{t}^{T} \sigma_{t}\left(v_{c}\right)>|x|
$$




\section{AUTOMAGIC}

Ratio of channels of high variance (CHV). The same logic applies to the ratio of channels, for which the standard deviation $\sigma$ of the voltage $v$ measures across all time points $t$ exceeds $x \mathrm{mV}$. This ratio is reflected in the channels of high variance $(\mathrm{CHV})$ criterion:

$$
C H V(x)=\frac{1}{C} \sum_{c}^{C} \sigma_{c}\left(v_{t}\right)>|x|
$$

Therefore, after preprocessing and interpolating the datasets of a project, quality measures with varying sensitivity (i.e. by applying variable thresholds) for high-amplitude noise are calculated. The effect of the different thresholds is illustrated in Figure 2. The choices of the quality measure thresholds should serve to optimize the sensitivity of high amplitude noise. We found the amplitude threshold of $30 \mathrm{mV}$ and the standard deviation thresholds of $15 \mathrm{mV}$ to be a good starting point to quantify remaining artifacts when data are high-pass filtered with bandpass of $0.5 \mathrm{~Hz}^{7}$. For data filtered with a higher bandpass, higher thresholds may be more suitable and can be changed by selecting the respective threshold in the respective dropdown menus in the Quality Classification panel.

\footnotetext{
${ }^{7}$ Note that this recommendation is based on data recorded with an 128 channels Netamps system (Electrical Geodesics, Eugene, Oregon) and may not apply to other recording systems.
} 


\section{AUTOMAGIC}

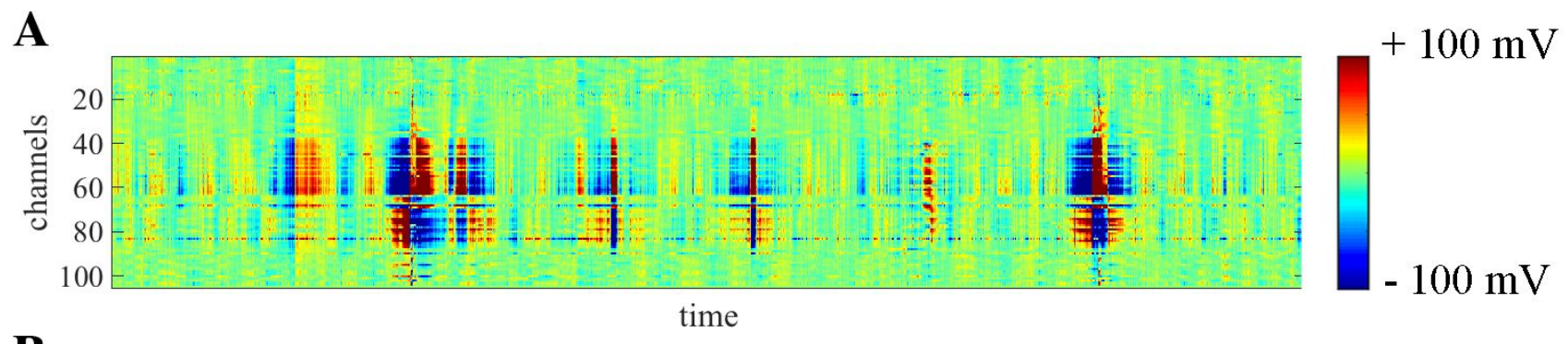

B

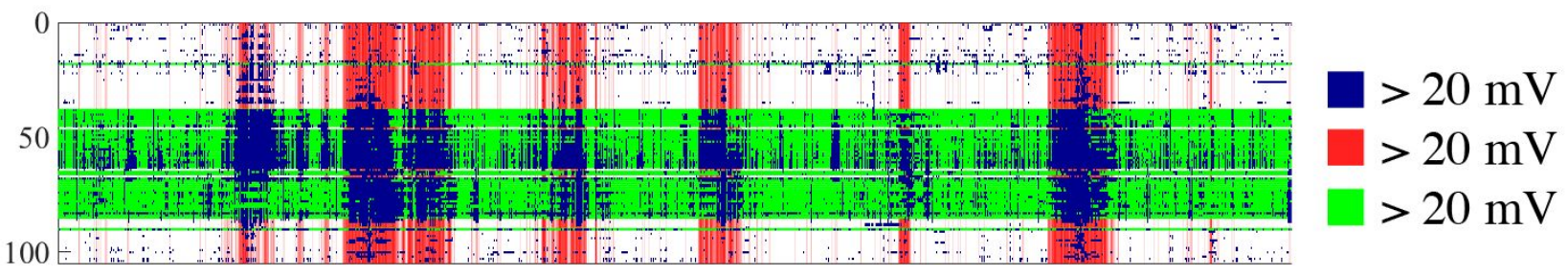

C

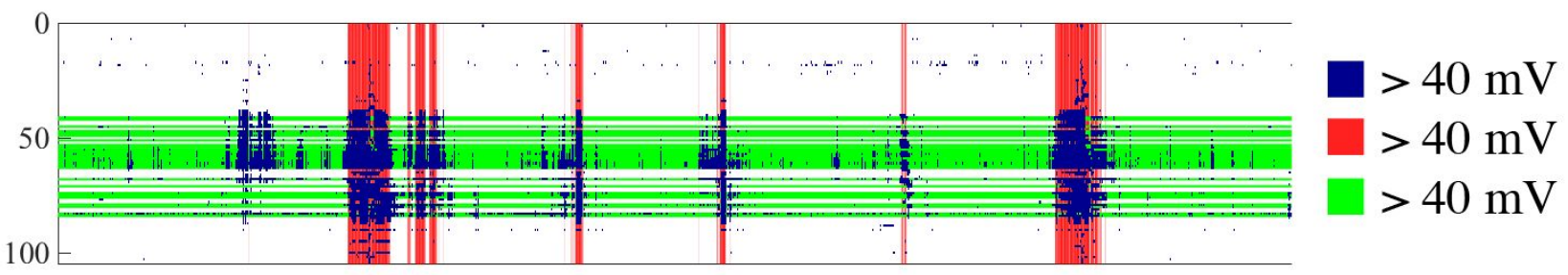

D

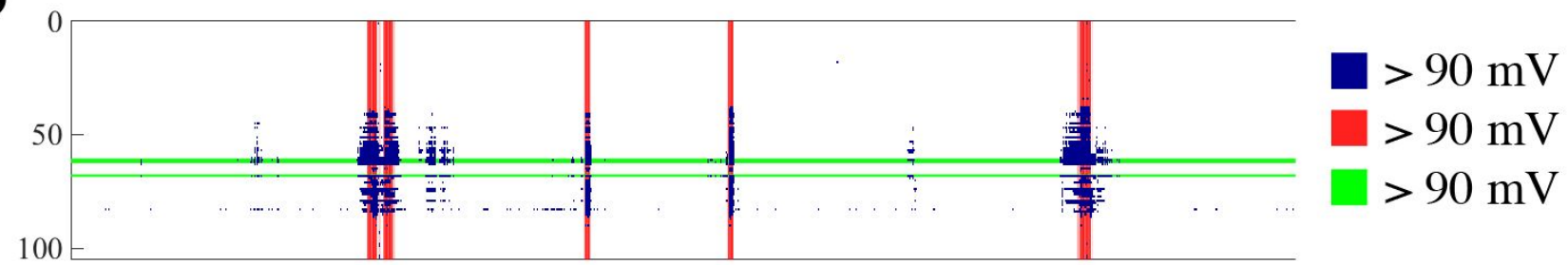

Figure 2. Effect of applying different thresholds to the quality measures. Panel A shows an exemplary EEG dataset as a heatmap scaled to $-100 \mathrm{mV}$ to $+100 \mathrm{mV}$, with considerable artifacts. A) Applying rather strict thresholds of $20 \mathrm{mV}$ results in large values for overall high amplitude criterion (OHA) (20\%), the timepoints of high variance criterion (THV) (25\%), and the channels of high variance criterion (CHV) (45\%). B) and C) show the effects of applying more liberal thresholds of $40 \mathrm{mV}$ and $90 \mathrm{mV}$, resulting in smaller values for OHA $(8 \%, 2 \%)$, THV $(10 \%, 4 \%)$, CHV $(26 \%, 3 \%)$. Blue areas indicate data points marked by the OHA criterion, red time windows indicate epochs marked in accordance with the THV criterion, green lines indicate channels marked in accordance with the CHV criterion.

We would like to emphasize that the rationale behind assessing quality with multiple measures is that the quality of a dataset strongly depends on the goal and specifics of the analysis. For instance, if a researcher is only interested in ERPs of very specific channels, she might ignore the CHV and RBC 
bioRxiv preprint first posted online Nov. 4, 2018; doi: http://dx.doi.org/10.1101/460469. The copyright holder for this preprint (which

was not peer-reviewed) is the author/funder, who has granted bioRxiv a license to display the preprint in perpetuity.

It is made available under a CC-BY-NC 4.0 International license.

\section{AUTOMAGIC}

criterion, and only consider that the channels of interest are free of artifacts. Alternatively, if there are many trials available in a dataset, the THV criterion could be relaxed. Therefore, the user can select the thresholds and the criteria, upon which the quality assessment is based. However, importantly, the thresholds are applied to all datasets of one project and therefore the quality standards are the same for all datasets.

\subsubsection{Quality classification}

Using a selection of the quality measures (OHA, THV, CHV, RBC) and specified thresholds, the user can classify the datasets of one project into three categories "Good", "OK", "Bad", by applying cutoffs for each quality measure. We provide three categories to allow testing whether effects of interest that can be delineated in very clean EEG data (i.e. "Good" category) also hold in noisier ("OK" category) data. By equating the thresholds of "OK" to the thresholds of the "Bad" category, the data can be included/excluded in a deterministic way for later analyses.

All the default values for thresholds and category cutoffs can be modified and therefore the user can compile samples in accordance with his/her own purposes. However, to restrict oneself in repeatedly compiling categories and running analyses until effects become true (i.e. P-hacking), the user can commit selected a categorical assignment by pressing "commit classification", which appends the letters "g" for "Good", "o" for "OK", and "b" for "Bad" to the file name of the preprocessed EEG dataset. The application of such quantitative quality measures and cutoffs makes it possible to compare the ratio of "Good", "OK", "Bad" categories between projects, providing insights into the comparability of the data quality of different projects/recording sites or recording apparatus and facilitate data selection for further analysis. 
bioRxiv preprint first posted online Nov. 4, 2018; doi: http://dx.doi.org/10.1101/460469. The copyright holder for this preprint (which

was not peer-reviewed) is the author/funder, who has granted bioRxiv a license to display the preprint in perpetuity.

It is made available under a CC-BY-NC 4.0 International license.

\section{AUTOMAGIC}

\subsection{BIDS integration}

Automagic can preprocess datasets in the BIDS EEG format. In addition, Automagic offers the export of a project into a brain imaging data structure (BIDS) compatible structure to facilitate data sharing. BIDS is a data sharing standard that has been originally developed for MRI data but now also encompasses other modalities, including an extension for EEG (Pernet et al., 2018a). The BIDS reflects a systematic way to organize data in a folder structure with dedicated names. An alternative standard to EEG BIDS following the same goal of enabling data sharing is the EEG Study Schema (ESS)

(Bigdely-Shamlo et al., 2016). We have decided to implement BIDS EEG (instead of the ESS) because the BIDS EEG can be readily combined to other BIDS extensions such as an extension for eye tracking, or fMRI that all follow the same basic structure.

Note, that Automagic uses its' own folder structure to allow an efficient management of growing datasets but the user can at any time export a project to a BIDS compatible format with a raw data folder with the BIDS compatible data files and structure, a derivative folder with the preprocessed data and the code that performs the computations to transform data of the raw to derivative. We encourage to share data using the BIDS as it facilitates communication, increases reproducibility and makes easier to develop data analysis pipelines.

\section{Validation}

\subsection{Methods}

Automagic utilizes mainly preprocessing methods that have been previously published and most of the methods have been validated (Bigdely-Shamlo et al., 2015; Mullen, 2012; Parra et al., 
bioRxiv preprint first posted online Nov. 4, 2018; doi: http://dx.doi.org/10.1101/460469. The copyright holder for this preprint (which was not peer-reviewed) is the author/funder, who has granted bioRxiv a license to display the preprint in perpetuity.

It is made available under a CC-BY-NC 4.0 International license.

\section{AUTOMAGIC}

2005; Winkler et al., 2014, 2011). The main aim of this section is to validate the effect of combining methods on the resulting preprocessed data to provide recommendations on the choice of preprocessing steps when using Automagic.

The goal of preprocessing is to separate and clean artifacts (i.e. signal of no interest) from physiological signals of interest; hence, our validation aims to delineate to what extent noise can be separated from the signal of interest. Since it is not possible to determine the ground-truth for the signal of interest (i.e. EEG signal with neuronal source) because the neural sources cannot be fully determined by the EEG signal (i.e. the inverse problem), often validations are performed by simulating EEG with known sources of noise. However, it is not trivial to model the variability of artifacts between subjects that is typically observed in real data. Hence, we follow an indirect, yet more realistic validation strategy. We will later provide details but first outline the basic idea behind this strategy: Considering the EEG of one person, we assume that the underlying neuronal activity during rest is relatively similar during periods of time where artifacts occur and periods of time with clean EEG. The EEG signals in the clean and artifact-contaminated time windows should to a great extent differ due to artifactual noise and not due to underlying differences in neuronal activity; hence, a valid preprocessing method should remove the artifactual noise and increase the similarity of key characteristics of periods of time where artifacts occur and periods of time without artifacts.

To test this, we used 52 EEG datasets (128 channels Netamps system (Electrical Geodesics, Eugene, Oregon), $\mathrm{Cz}$ recording reference, sampling rate: $500 \mathrm{~Hz}, 1 \mathrm{~Hz}$ high-pass filtered) of 26 healthy elderly subjects (mean age $71.5, \mathrm{SD} \pm 5.1$ ) during a passive resting task with opened eyes. The data and code that have been used are available online https://osf.io/5e $74 \mathrm{x} /$. The study was approved by the ethics committee of the canton of Zurich, Switzerland (BASEC-Nr: 2017-00226) and informed consent was obtained of each subject. The channels that were placed in the most ventral ring of the cap (E32, 
bioRxiv preprint first posted online Nov. 4, 2018; doi: http://dx.doi.org/10.1101/460469. The copyright holder for this preprint (which was not peer-reviewed) is the author/funder, who has granted bioRxiv a license to display the preprint in perpetuity.

It is made available under a CC-BY-NC 4.0 International license.

\section{AUTOMAGIC}

E48, E49, E56, E63, E68, E73, E81, E88, E94, E99, E107, E113, E119) were discarded. EOG channels were E1, E32, E8, E14. E17, E21, E25, E125, E126, E127, E128.

The data of each subject, consisting of five $16 \mathrm{~s}$ epochs $(=40,000$ time frames (TFs)), were first scanned for artifacts by identifying the TFs where the standard deviation across channels is larger than $25 \mathrm{mV}$. Then, the EEG was epoched into $2 \mathrm{~s}$ segments. If a TF with a standard deviation greater than $25 \mathrm{mV}$ was within an epoch, the epoch was marked as a bad epoch (i.e. epoch with artifact); otherwise, a good epoch (i.e. epoch without artifact).

Good and bad epochs were then concatenated to separate datasets. To avoid datasets with exceedingly small number of time points, datasets with fewer than 10,000 TFs of either good or bad epochs were discarded for the further analysis. To make the good and bad datasets of a subject comparable, the length of the dataset with more TFs was reduced to the length of the dataset with shorter length, by randomly choosing the corresponding number of epochs. This resulted in 52 datasets (for each subject one good and one bad dataset) with on average 22,000 TFs (min: 10,000 TFs, max: 30’000 TFs, std =6,112 TFs).

In a next step, we set up and ran 18 different variations of preprocessing in AUTOMAGIC. In a first set of variations, we preprocessed the datasets by only interpolating bad channels that were identified by PREP and/or clean_rawdata(), using the respective default settings (see section Bad channel identification and Bad channel interpolation). These bad channel interpolating methods were then combined with artifact correction methods of either MARA or rPCA and with a combination with EOG regression (with their default settings, see section Artifact correction). 
bioRxiv preprint first posted online Nov. 4, 2018; doi: http://dx.doi.org/10.1101/460469. The copyright holder for this preprint (which

\section{AUTOMAGIC}

\subsection{Results}

\subsubsection{Quantitative characteristics}

The results of the preprocessing are summarized in Figure 3. The quality measures of the good and bad datasets were calculated and serve as comparison of the extent to which artifacts are present in the data before and after the respective preprocessing variation. Before preprocessing (Figure 3, leftmost column), the bad epochs show substantially more noise, (reflected in higher signal amplitudes) in all quality measures than the good epochs. In general, the more preprocessing methods are applied, the more noise and arguably overall signal of interest (see Figure 3 panel B) is removed. Thus, from this information alone it is not possible to assess an optimal preprocessing variation that balances removal of noise and signal. We will turn to this later.

Considering the ratio of identified bad channels, clean_rawdata() detected on average $19 \%$ bad channels in the bad datasets and $15 \%$ in the good datasets, compared to fewer bad channels identified PREP ( $15 \%$ in bad datasets, $13 \%$ in good datasets). The combination of bad channel identification methods together yielded $22 \%$ of bad channels in the bad dataset and $18 \%$ of bad channels in the good datasets. Therefore, both bad channel identification pipelines identify to a great extent similar but not identical bad channels.

Panel G shows the percentage retained variance after MARA. This metric shows how much variance is retained after back-projecting the non-artifactual (clean) ICs. Note that retained variance is influenced by how clean the data are when entering the ICA of MARA. Therefore, more retained variance does not per se indicate less noisy data. If MARA is used without a preceding EOG regression, substantially more variance is removed from the data in the bad datasets (on average $52 \%$ retained variance in good datasets, $27 \%$ retained variance in bad datasets) whereas this difference is substantially smaller when MARA is used after EOG regression (on average 52\% retained variance in 
bioRxiv preprint first posted online Nov. 4, 2018; doi: http://dx.doi.org/10.1101/460469. The copyright holder for this preprint (which was not peer-reviewed) is the author/funder, who has granted bioRxiv a license to display the preprint in perpetuity.

It is made available under a CC-BY-NC 4.0 International license.

\section{AUTOMAGIC}

good datasets, $42 \%$ retained variance in bad datasets). This indicates that the EOG regression and MARA may to some extent remove similar artifacts.

In addition to these rather global quality measures, we computed for the data before preprocessing (high-pass filtered at $1 \mathrm{~Hz}$ ) and the 18 variations of preprocessing power spectral densities (PSDs) for a frequency range of $1 \mathrm{~Hz}$ to $45 \mathrm{~Hz}$ (using the spectopo() function of EEGLAB with 2 times oversampling) for the channels Fz, Cpz, and Oz. Panel (H) shows to what extent the good and bad PSDs differ when aggregating spectral power bands (mean of "Fz", “Cpz”, “Oz”, delta: 1.5 - 6 Hz, theta: $6.5-8 \mathrm{~Hz}$, alpha $_{1}: 8.5-10 \mathrm{~Hz}$, alpha $_{2}: 10.5-12 \mathrm{~Hz}$, beta $: 12.5-18 \mathrm{~Hz}$, beta 2 : $18.5-21 \mathrm{~Hz}$, beta $_{3}: 21.5$ - $30 \mathrm{~Hz}$, gamma: $30-45 \mathrm{~Hz}$ ). Overall it becomes evident that the bad datasets have overall higher PSDs compared to the good datasets. Considering the different preprocessing variations, those with bad channel interpolation only and bad channel interpolation in combination with rPCA leave large differences between good and bad data in lower frequency bands, which are substantially smaller when at least EOG regression or MARA is applied.

To further quantify these findings, we statistically compared the "good" and "bad" PSDs of each subject. Recall that a valid preprocessing method should remove the artifactual noise and remove differences in PSDs in the good and bad epochs of subjects. To test this, we used paired-permutation tests, where we count how many times for each frequency the sum of the differences between "good" and "bad" PSDs is larger than the sum of the differences when the "good" and "bad" PSDs are 10,000 times pairwise randomly shuffled. The ratio of randomly exceeding the actual sum of differences reflects the empirical probability $p$ that the actually observed sum of differences is observed by chance. The permutation tests are performed for each frequency bin $(1-45 \mathrm{~Hz})$ for the channels $\mathrm{Oz}, \mathrm{Cpz}$ and Fz. The results of these tests are illustrated in Figure 3 panel I, where the frequency bins (x-axis), in which the PSD differs significantly $(\mathrm{p}<0.001)$ between the good and bad datasets are drawn in black 


\section{AUTOMAGIC}

for the channels $\mathrm{Oz}, \mathrm{Cpz}$ and $\mathrm{Fz}$ (each channel in one row) and for each preprocessing variation. The results suggest that after applying any bad channel rejection method in combination with artifact correction using MARA, no significant differences in the PSD across the frequencies of 1 - $45 \mathrm{~Hz}$ are observable. In contrast, using bad channel rejection only or a combination thereof with rPCA and EOG regression leaves substantially more frequency bins that differ significantly. 
bioRxiv preprint first posted online Nov. 4, 2018; doi: http://dx.doi.org/10.1101/460469. The copyright holder for this preprint (which was not peer-reviewed) is the author/funder, who has granted bioRxiv a license to display the preprint in perpetuity.

It is made available under a CC-BY-NC 4.0 International license.

\section{AUTOMAGIC}
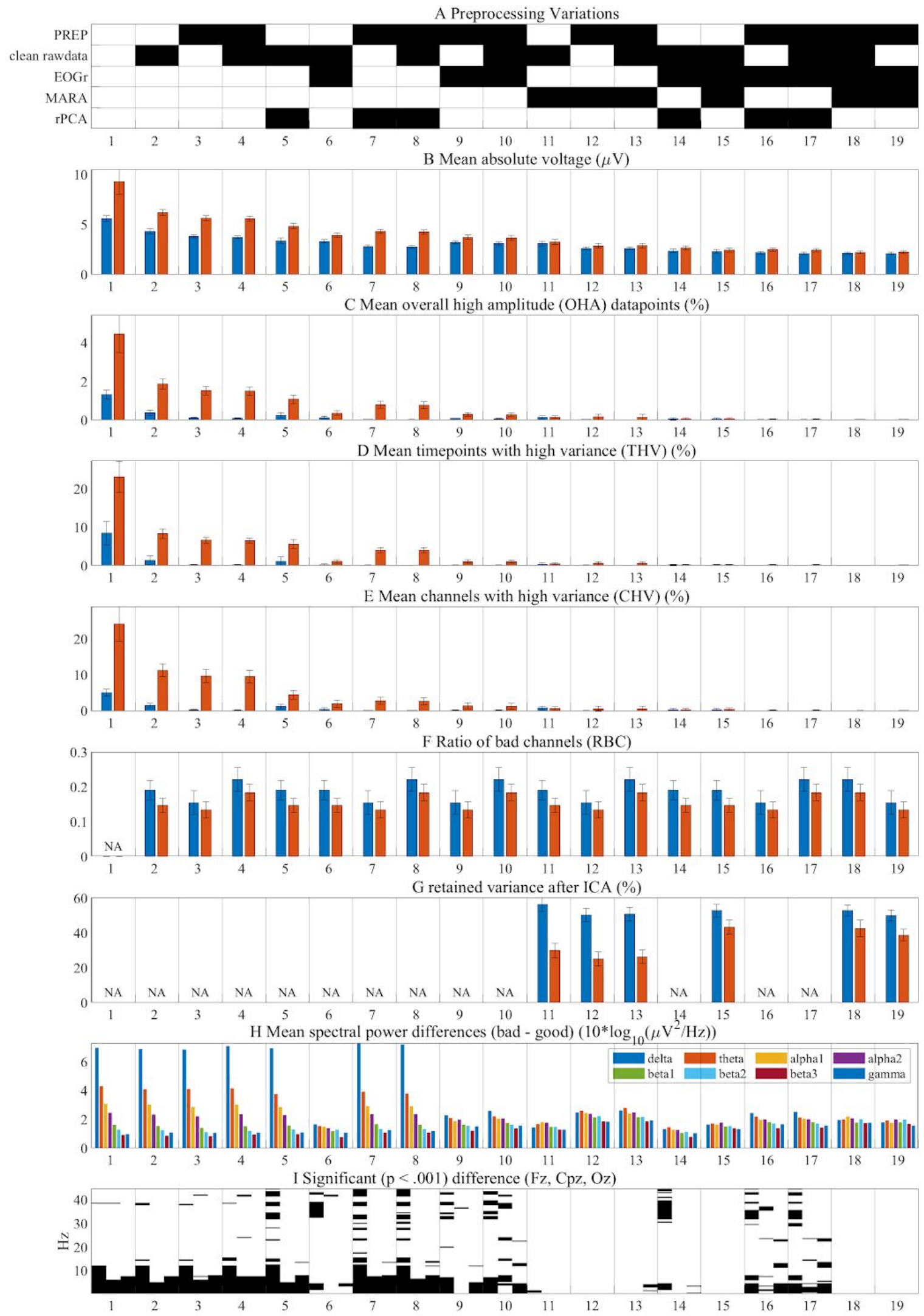
bioRxiv preprint first posted online Nov. 4, 2018; doi: http://dx.doi.org/10.1101/460469. The copyright holder for this preprint (which

was not peer-reviewed) is the author/funder, who has granted bioRxiv a license to display the preprint in perpetuity.

It is made available under a CC-BY-NC 4.0 International license.

\section{AUTOMAGIC}

Figure 3. Validation results. Panel A shows the combinations of selected (black) preprocessing methods. The first column of the figure reflects the quality measures of the EEG data before the preprocessing. The combinations are sorted with respect to mean absolute voltage shown in panel B with blue bars for the good datasets and red bars for the bad datasets; hence, the order indicates how much signal is subtracted by the preprocessing variations. Panels C-E depict the results of applying the quality measures of overall high amplitude data points (OHA), time points with high variance (THV), and channels with high variance (CHV) (see section Quality measures for details on the calculation). Panel F shows the ratio of bad channels, as identified by the bad channel identification methods. In panel $\mathrm{G}$ the percentage of retained variance after the back-projection of non-artifactual ICs in MARA is shown. The difference between the spectra power in frequency bands of the bad minus the good datasets is shown in panel $\mathrm{H}$. Panel I illustrates in which frequencies the power differs significantly (black bars: $\mathrm{p}<0.001$ ) in the channels $\mathrm{Fz}, \mathrm{Cpz}$, and $\mathrm{Oz}$ (each row reflects one channel).

\subsubsection{Qualitative characteristics}

To assess to what extent signal (and not only artifacts) are removed, we consider qualitative characteristics of the PSDs. Figure 4A shows PSDs in the channels Fz, Pcz and Oz with only $1 \mathrm{~Hz}$ filtered data. Figure 4B shows the PSD after having applied PREP, Figure 4C PREP and EOGr, and Figure 4D PREP and MARA. The full set of plots of all variations are shown in Appendix A.

It is evident that only applying bad channel identification (i.e. PREP and clean_rawdata()) and interpolation leaves substantial differences between good and bad datasets in frequency ranges from 1 to $20-30 \mathrm{~Hz}$ (see also Appendix A. Figure $1 \mathrm{~B}-\mathrm{D})$. Considering the different combinations of artifact correction methods (i.e. EOGr, MARA, rPCA) and bad channel identification methods demonstrates that MARA is able to correct for most artifacts in contrast to EOGr and rPCA, which leave substantial differences between good and bad datasets (see also Appendix A. Figure 1 E-S). Furthermore, the results suggest that a combination of PREP (or clear_rawdata()) and MARA is sufficient to remove (almost) all significant differences in the PSDs.

To estimate to what extent the preprocessing variations balance the removal of noise compared to retaining the signal of interest, we consider the characteristic alpha peak in Oz. We estimated the alpha peak power amplitude using the method by Haller et al. 2018 (2018), where we calculate the 


\section{AUTOMAGIC}

mean alpha peak power from the mean (across subjects) PSD in the frequency range of $8.5 \mathrm{~Hz}$ to $12 \mathrm{~Hz}$ for each preprocessing variation. Even if the amplitude of the alpha peak is smaller with opened eyes compared to closed eyes (Klimesch, 1999), the results show that before the preprocessing the alpha peak power is more than double in the good datasets compared to the alpha peak power in the bad datasets (see Figure 4E). With additional preprocessing, the alpha peak power in Oz in the bad datasets increases (Figure 4E, red bars) whereas the alpha peak in the good dataset (blue bars) does not substantially decrease, as it would if the signal of interest were removed by the preprocessing. This suggests that the preprocessing (for instance using a variation of bad channel identification), MARA (and EOGr) removes to a great extent artifactual signal and not signal of interest (i.e. signal in the alpha band). 
bioRxiv preprint first posted online Nov. 4, 2018; doi: http://dx.doi.org/10.1101/460469. The copyright holder for this preprint (which was not peer-reviewed) is the author/funder, who has granted bioRxiv a license to display the preprint in perpetuity.

It is made available under a CC-BY-NC 4.0 International license.

\section{AUTOMAGIC}

A

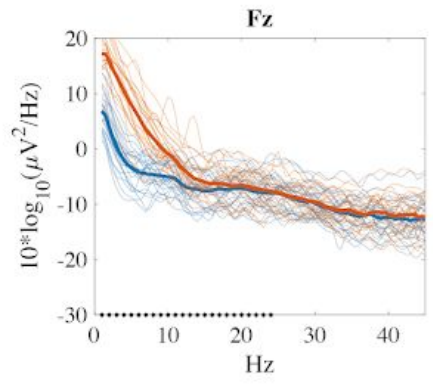

B

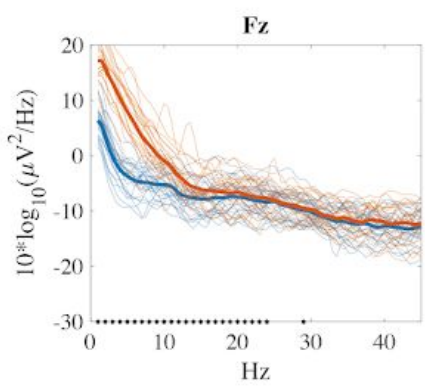

C

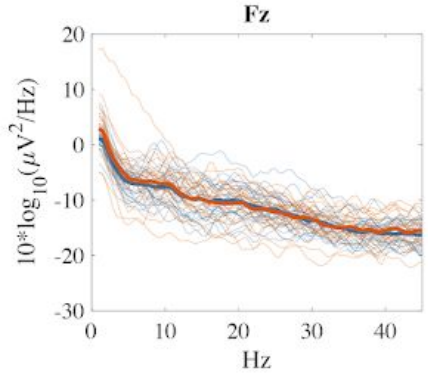

D

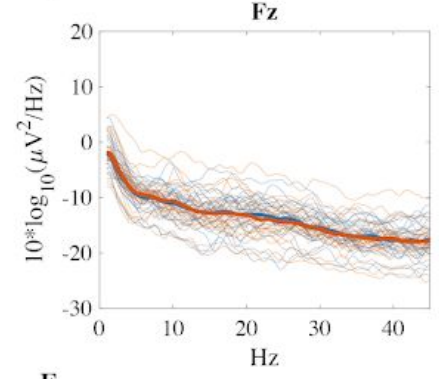

E
$1 \mathrm{~Hz}$ high pass-filtered EEG

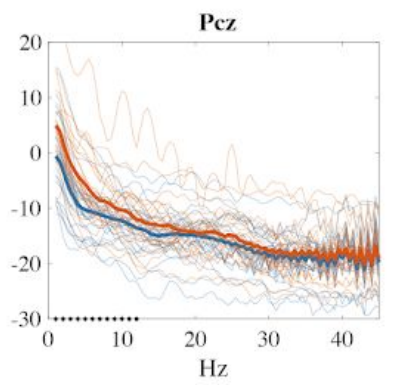

$1 \mathrm{~Hz}+\mathrm{PREP}$

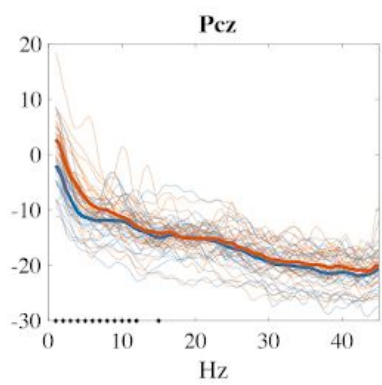

$1 \mathrm{~Hz}+\mathrm{PREP}+\mathrm{MARA}$
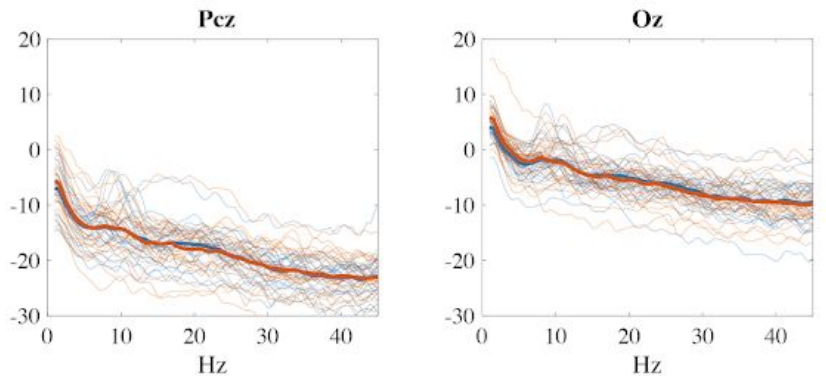

$1 \mathrm{~Hz}+\mathrm{PREP}+$ clean rawdata ()$+\mathrm{MARA}+\mathrm{EOGr}$

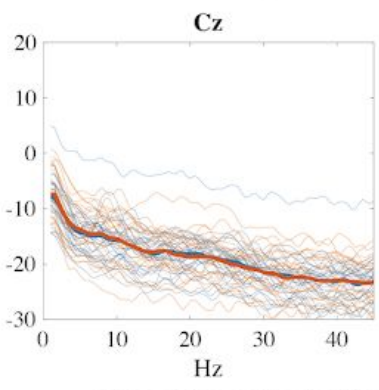

Alpha peak amplitude at $\mathrm{Oz}$
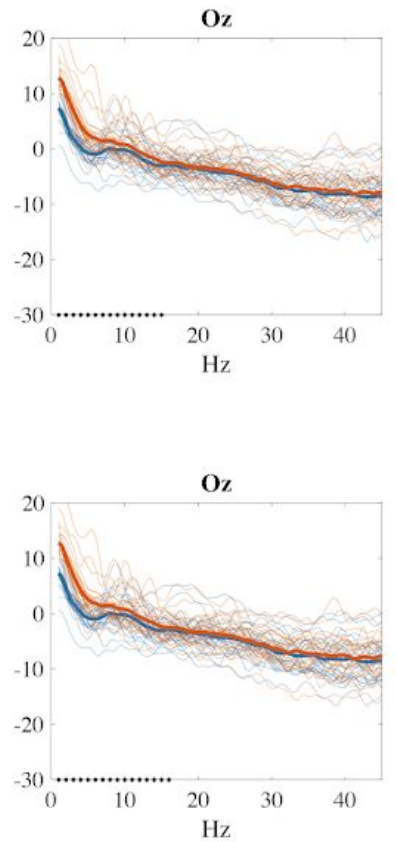

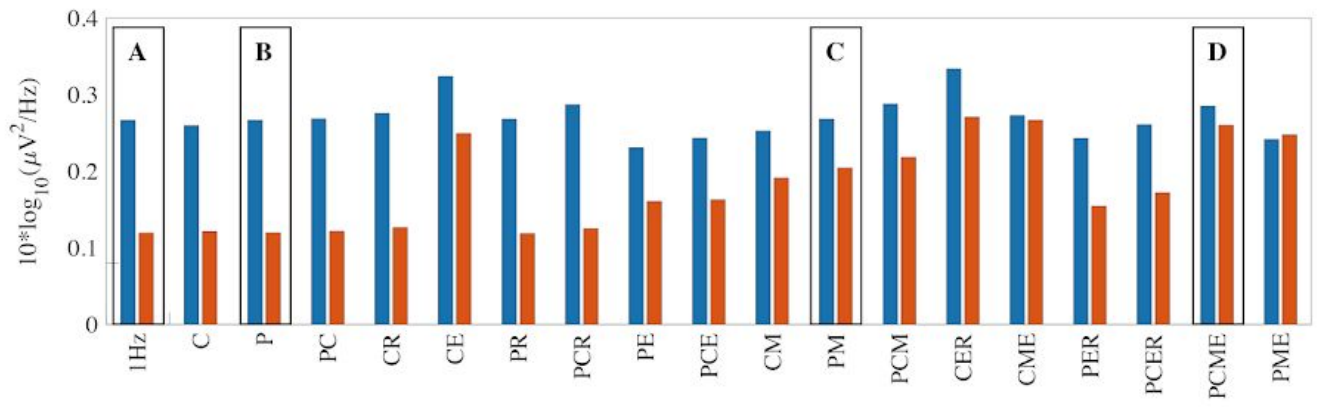


bioRxiv preprint first posted online Nov. 4, 2018; doi: http://dx.doi.org/10.1101/460469. The copyright holder for this preprint (which

was not peer-reviewed) is the author/funder, who has granted bioRxiv a license to display the preprint in perpetuity.

It is made available under a CC-BY-NC 4.0 International license.

\section{AUTOMAGIC}

Figure 4. PSDs with different preprocessing variations. The PSDs of good (blue lines) and bad (red lines) datasets are shown for the channels Fz, Pcz, and Oz. The asterisks indicate significantly $(\mathrm{p}<0.001)$ differing PSD at the specific frequency bin. Panel E shows the alpha peak power in $\mathrm{Oz}$ in good (blue) and bad (red) data after the preprocessing variations (in identical order as in Figure 2). The black boxes point to the respective preprocessing variation shown in panels $\mathrm{A}-\mathrm{F}$ above. $(\mathrm{P}=\mathrm{PREP}, \mathrm{C}=$ clean rawdata ()$, \mathrm{M}=\mathrm{MARA}, \mathrm{R}=\mathrm{rPCA}, \mathrm{E}$ $=\mathrm{EOGr}$ )

\section{Discussion}

The number of large-scale studies using EEG is limited compared to large-scale MRI and fMRI studies. As we argue, this is not because the EEG signals offers less informative insights into brain (dys-)functioning, but is manifest mainly in two unresolved issues. First, the quality of EEG recordings often substantially differs between subjects and currently there is no objective way of quantifying the quality and hence these differences. This renders the typically inevitable process of excluding subjects from analyses due to exceeding contamination of artifacts highly subjective. This not only impedes a precise methodological replication but also seduces researchers into trying out various combinations (i.e. P-hacking), further decreasing the chance of replication. The second reason is technical. Currently no software solution exists that controls and manages the preprocessing of ongoing and dynamically growing studies. To address these challenges, we developed AUTOMAGIC, an open-source MATLAB toolbox that wraps currently available preprocessing methods and offers standardized quality assessment for growing studies. We introduced the functionality of AUTOMAGIC and investigated the effect of applying combinations of methods on a sample of resting EEG data. This validation revealed that a combination of applying a pipeline of bad channel identification algorithms and MARA, an

ICA-based artifact correction method, is sufficient to reduce a large number of artifacts.

There are several limitations to the presented validation and also to the use of AUTOMAGIC.

First, the ratio between the duration of the data and the number of channels used for the validation is 
bioRxiv preprint first posted online Nov. 4, 2018; doi: http://dx.doi.org/10.1101/460469. The copyright holder for this preprint (which was not peer-reviewed) is the author/funder, who has granted bioRxiv a license to display the preprint in perpetuity.

It is made available under a CC-BY-NC 4.0 International license.

\section{AUTOMAGIC}

rather low and may be suboptimal for an ICA decomposition. However, we believe that the result of the validation —namely, that a combination of MARA and a bad channel identification pipeline successfully removes noise while preserving the characteristics of resting EEG PSDs (e.g. alpha peak)—still holds. With more data, the ICs would be estimated more robustly and hence the results should improve. Yet, it is also possible that the performance of correcting artifacts with the rPCA and EOGr improves with more data.

The results of the validation are furthermore limited to testing the effects of preprocessing on the PSDs of resting EEG with eyes open. Other signals of interests (such as characteristics of event related potentials (ERP), features in time-frequency decomposition, source localization and connectivity measures) may favor different combinations of preprocessing and should be tested on the respective datasets. We chose resting EEG with open eyes because we aimed to use realistic EEG data with a similar number of clean segments and segments of EEG that were clearly contaminated with artifacts. Under the assumption that the true underlying neuronal activity is similar in the artifactual and clean epochs, we assessed the effectiveness of the methods by considering the extent of increase in the similarity of key characteristics of the good and bad datasets.

\section{Conclusion}

We introduced AUTOMAGIC an open-source MATLAB toolbox that incorporates currently available EEG preprocessing methods and offers new objective standardized quality assessment for growing studies. AUTOMAGIC fosters transparency and data sharing in EEG by complying with the BIDS EEG standard and providing detailed logging of all performed processes. With this we hope to facilitate 
bioRxiv preprint first posted online Nov. 4, 2018; doi: http://dx.doi.org/10.1101/460469. The copyright holder for this preprint (which

was not peer-reviewed) is the author/funder, who has granted bioRxiv a license to display the preprint in perpetuity.

It is made available under a CC-BY-NC 4.0 International license.

\section{AUTOMAGIC}

future large scale EEG studies to advance the replicability of EEG research and the detection of

EEG-based biomarkers.

\section{Author contributions}

A.P, A.B. and N.L. developed the software. A.P. and N.L. designed the validation. A.P. analyzed the data. A.P. and N.L. wrote the paper.

\section{Competing financial interests}

The authors declare no competing financial interests.

\section{Funding}

This work was supported by the Swiss National Science Foundation [100014_175875].

\section{References}

Alexander, L.M., Escalera, J., Ai, L., Andreotti, C., Febre, K., Mangone, A., Vega-Potler, N., Langer, N., Alexander, A., Kovacs, M., Litke, S., O’Hagan, B., Andersen, J., Bronstein, B., Bui, A., Bushey, M., Butler, H., Castagna, V., Camacho, N., Chan, E., Citera, D., Clucas, J., Cohen, S., Dufek, S., Eaves, M., Fradera, B., Gardner, J., Grant-Villegas, N., Green, G., Gregory, C., Hart, E., Harris, S., Horton, M., Kahn, D., Kabotyanski, K., Karmel, B., Kelly, S.P., Kleinman, K., Koo, B., Kramer, E., Lennon, E., Lord, C., Mantello, G., Margolis, A., Merikangas, K.R., Milham, J., Minniti, G., Neuhaus, R., Levine, A., Osman, Y., Parra, L.C., Pugh, K.R., Racanello, A., Restrepo, A., Saltzman, T., Septimus, B., Tobe, R., Waltz, R., Williams, A., Yeo, A., Castellanos, F.X., Klein, A., Paus, T., Leventhal, B.L., Craddock, R.C., Koplewicz, H.S., Milham, M.P., 2017. An open resource for transdiagnostic research in pediatric mental health and learning disorders. Sci Data 4, 170181. https://doi.org/10.1038/sdata.2017.181

Bigdely-Shamlo, N., Makeig, S., Robbins, K.A., 2016. Preparing Laboratory and Real-World EEG Data for Large-Scale Analysis: A Containerized Approach. Front. Neuroinform. 10, 7. https://doi.org/10.3389/fninf.2016.00007

Bigdely-Shamlo, N., Mullen, T., Kothe, C., Su, K.-M., Robbins, K.A., 2015. The PREP pipeline: standardized preprocessing for large-scale EEG analysis. Front. Neuroinform. 9, 16. https://doi.org/10.3389/fninf.2015.00016

Bigdely-Shamlo, N., Touryan, J., Ojeda, A., Kothe, C., 2018a. Automated EEG mega-analysis I: Spectral and amplitude characteristics across studies. bioRxiv.

Bigdely-Shamlo, N., Touyran, J., Ojeda, A., Kothe, C., 2018b. Automated EEG mega-analysis II: Cognitive aspects of event related features. bioRxiv.

Boutros, N., Fraenkel, L., Feingold, A., 2005. A four-step approach for developing diagnostic tests in psychiatry: EEG in ADHD as a test case. J. Neuropsychiatry Clin. Neurosci. 17, 455-464. 


\section{AUTOMAGIC}

https://doi.org/10.1176/jnp.17.4.455

Boutros, N.N., Arfken, C., Galderisi, S., Warrick, J., Pratt, G., Iacono, W., 2008. The status of spectral EEG abnormality as a diagnostic test for schizophrenia. Schizophr. Res. 99, 225-237. https://doi.org/10.1016/j.schres.2007.11.020

Cecchi, M., Moore, D.K., Sadowsky, C.H., Solomon, P.R., Doraiswamy, P.M., Smith, C.D., Jicha, G.A., Budson, A.E., Arnold, S.E., Fadem, K.C., 2015. A clinical trial to validate event-related potential markers of Alzheimer's disease in outpatient settings. Alzheimers. Dement. 1, 387-394. https://doi.org/10.1016/j.dadm.2015.08.004

Chaumon, M., Bishop, D.V.M., Busch, N.A., 2015. A practical guide to the selection of independent components of the electroencephalogram for artifact correction. J. Neurosci. Methods 250, 47-63. https://doi.org/10.1016/j.jneumeth.2015.02.025

Cowley, B.U., Korpela, J., 2018. Computational Testing for Automated Preprocessing 2: Practical Demonstration of a System for Scientific Data-Processing Workflow Management for High-Volume EEG. Front. Neurosci. 12, 236. https://doi.org/10.3389/fnins.2018.00236

Cowley, B.U., Korpela, J., Torniainen, J., 2017. Computational testing for automated preprocessing: a Matlab toolbox to enable large scale electroencephalography data processing. PeerJ Comput. Sci. 3, e108. https://doi.org/10.7717/peerj-cs.108

Cuthbert, B.N., Insel, T.R., 2013. Toward the future of psychiatric diagnosis: the seven pillars of RDoC. BMC Med. 11, 126. https://doi.org/10.1186/1741-7015-11-126

da Cruz, J.R., Chicherov, V., Herzog, M.H., Figueiredo, P., 2018. An automatic pre-processing pipeline for EEG analysis (APP) based on robust statistics. Clin. Neurophysiol. 129, 1427-1437. https://doi.org/10.1016/j.clinph.2018.04.600

Delorme, A., Makeig, S., 2004. EEGLAB: an open source toolbox for analysis of single-trial EEG dynamics including independent component analysis. J. Neurosci. Methods 134, 9-21. https://doi.org/10.1016/j.jneumeth.2003.10.009

Delorme, A., Sejnowski, T., Makeig, S., 2007. Enhanced detection of artifacts in EEG data using higher-order statistics and independent component analysis. Neuroimage 34, 1443-1449. https://doi.org/10.1016/j.neuroimage.2006.11.004

Di Martino, A., Yan, C.-G., Li, Q., Denio, E., Castellanos, F.X., Alaerts, K., Anderson, J.S., Assaf, M., Bookheimer, S.Y., Dapretto, M., Deen, B., Delmonte, S., Dinstein, I., Ertl-Wagner, B., Fair, D.A., Gallagher, L., Kennedy, D.P., Keown, C.L., Keysers, C., Lainhart, J.E., Lord, C., Luna, B., Menon, V., Minshew, N.J., Monk, C.S., Mueller, S., Müller, R.-A., Nebel, M.B., Nigg, J.T., O’Hearn, K., Pelphrey, K.A., Peltier, S.J., Rudie, J.D., Sunaert, S., Thioux, M., Tyszka, J.M., Uddin, L.Q., Verhoeven, J.S., Wenderoth, N., Wiggins, J.L., Mostofsky, S.H., Milham, M.P., 2014. The autism brain imaging data exchange: towards a large-scale evaluation of the intrinsic brain architecture in autism. Mol. Psychiatry 19, 659-667. https://doi.org/10.1038/mp.2013.78

Duncan, C.C., Barry, R.J., Connolly, J.F., Fischer, C., Michie, P.T., Näätänen, R., Polich, J., Reinvang, I., Van Petten, C., 2009. Event-related potentials in clinical research: guidelines for eliciting, recording, and quantifying mismatch negativity, P300, and N400. Clin. Neurophysiol. 120, 1883-1908. https://doi.org/10.1016/j.clinph.2009.07.045

Eickhoff, S., Nichols, T.E., Van Horn, J.D., Turner, J.A., 2016. Sharing the wealth: Neuroimaging data repositories. Neuroimage 124, 1065-1068. https://doi.org/10.1016/j.neuroimage.2015.10.079

Gabard-Durnam, L.J., Mendez Leal, A.S., Wilkinson, C.L., Levin, A.R., 2018. The Harvard Automated Processing Pipeline for Electroencephalography (HAPPE): Standardized Processing Software for Developmental and High-Artifact Data. Front. Neurosci. 12, 97. https://doi.org/10.3389/fnins.2018.00097

Gorgolewski, K.J., Auer, T., Calhoun, V.D., Craddock, R.C., Das, S., Duff, E.P., Flandin, G., Ghosh, S.S., Glatard, T., Halchenko, Y.O., Handwerker, D.A., Hanke, M., Keator, D., Li, X., Michael, Z., Maumet, C., Nichols, B.N., Nichols, T.E., Pellman, J., Poline, J.-B., Rokem, A., Schaefer, G., Sochat, V., Triplett, W., Turner, J.A., Varoquaux, G., Poldrack, R.A., 2016. The brain imaging data structure, a format for 


\section{AUTOMAGIC}

organizing and describing outputs of neuroimaging experiments. Sci Data 3, 160044. https://doi.org/10.1038/sdata.2016.44

Haller, M., Donoghue, T., Peterson, E., Varma, P., Sebastian, P., Gao, R., Noto, T., Knight, R.T., Shestyuk, A., Voytek, B., 2018. Parameterizing neural power spectra. bioRxiv. https://doi.org/10.1101/299859

Hatz, F., Hardmeier, M., Bousleiman, H., Rüegg, S., Schindler, C., Fuhr, P., 2015. Reliability of fully automated versus visually controlled pre- and post-processing of resting-state EEG. Clin. Neurophysiol. 126, 268-274. https://doi.org/10.1016/j.clinph.2014.05.014

Jelic, V., Kowalski, J., 2009. Evidence-based evaluation of diagnostic accuracy of resting EEG in dementia and mild cognitive impairment. Clin. EEG Neurosci. 40, 129-142. https://doi.org/10.1177/155005940904000211

Jung, T.P., Makeig, S., Humphries, C., Lee, T.W., McKeown, M.J., Iragui, V., Sejnowski, T.J., 2000. Removing electroencephalographic artifacts by blind source separation. Psychophysiology 37, 163-178.

Kappenman, E.S., Luck, S.J., 2010. The effects of electrode impedance on data quality and statistical significance in ERP recordings. Psychophysiology 47, 888-904. https://doi.org/10.1111/j.1469-8986.2010.01009.x

Kapur, S., Phillips, A.G., Insel, T.R., 2012. Why has it taken so long for biological psychiatry to develop clinical tests and what to do about it? Mol. Psychiatry 17, 1174-1179. https://doi.org/10.1038/mp.2012.105

Keil, A., Debener, S., Gratton, G., Junghöfer, M., Kappenman, E.S., Luck, S.J., Luu, P., Miller, G.A., Yee, C.M., 2014. Committee report: publication guidelines and recommendations for studies using electroencephalography and magnetoencephalography. Psychophysiology 51, 1-21. https://doi.org/10.1111/psyp.12147

Klimesch, W., 1999. EEG alpha and theta oscillations reflect cognitive and memory performance: a review and analysis. Brain Res. Brain Res. Rev. 29, 169-195.

Langer, N., Ho, E.J., Alexander, L.M., Xu, H.Y., Jozanovic, R.K., Henin, S., Petroni, A., Cohen, S., Marcelle, E.T., Parra, L.C., Milham, M.P., Kelly, S.P., 2017a. A resource for assessing information processing in the developing brain using EEG and eye tracking. Sci Data 4, 170040. https://doi.org/10.1038/sdata.2017.40

Langer, N., Ho, E.J., Pedroni, A., Alexander, L.M., Marcelle, E.T., Schuster, K., Milham, M.P., Kelly, S.P., 2017b. A multi-modal approach to decomposing standard neuropsychological test performance: Symbol Search. bioRxiv. https://doi.org/10.1101/200998

Levin, A.R., Méndez Leal, A.S., Gabard-Durnam, L.J., O’Leary, H.M., 2018. BEAPP: The Batch Electroencephalography Automated Processing Platform. Front. Neurosci. 12, 513. https://doi.org/10.3389/fnins.2018.00513

Lin, Z., Chen, M., Ma, Y., 2010. The Augmented Lagrange Multiplier Method for Exact Recovery of Corrupted Low-Rank Matrices. arXiv [math.OC].

Lund, T.R., Sponheim, S.R., Iacono, W.G., Clementz, B.A., 1995. Internal consistency reliability of resting EEG power spectra in schizophrenic and normal subjects. Psychophysiology 32, 66-71. https://doi.org/10.1111/j.1469-8986.1995.tb03407.x

Mognon, A., Jovicich, J., Bruzzone, L., Buiatti, M., 2011. ADJUST: An automatic EEG artifact detector based on the joint use of spatial and temporal features. Psychophysiology 48, 229-240. https://doi.org/10.1111/j.1469-8986.2010.01061.x

Mueller, S.G., Weiner, M.W., Thal, L.J., Petersen, R.C., Jack, C.R., Jagust, W., Trojanowski, J.Q., Toga, A.W., Beckett, L., 2005. Ways toward an early diagnosis in Alzheimer's disease: the Alzheimer's Disease Neuroimaging Initiative (ADNI). Alzheimers. Dement. 1, 55-66. https://doi.org/10.1016/j.jalz.2005.06.003

Mullen, T., 2012. CleanLine EEGLAB plugin. San Diego, CA: Neuroimaging Informatics Toolsand Resources Clearinghouse (NITRC).

Mullen, T., Kothe, C., Chi, Y.M., Ojeda, A., Kerth, T., Makeig, S., Cauwenberghs, G., Jung, T.-P., 2013. Real-time modeling and 3D visualization of source dynamics and connectivity using wearable EEG. Conf. Proc. IEEE Eng. Med. Biol. Soc. 2013, 2184-2187. https://doi.org/10.1109/EMBC.2013.6609968 Näpflin, M., Wildi, M., Sarnthein, J., 2007. Test-retest reliability of resting EEG spectra validates a statistical 


\section{AUTOMAGIC}

signature of persons. Clin. Neurophysiol. 118, 2519-2524. https://doi.org/10.1016/j.clinph.2007.07.022

Nolan, H., Whelan, R., Reilly, R.B., 2010. FASTER: Fully Automated Statistical Thresholding for EEG artifact Rejection. J. Neurosci. Methods 192, 152-162. https://doi.org/10.1016/j.jneumeth.2010.07.015

Olvet, D.M., Hajcak, G., 2008. The error-related negativity (ERN) and psychopathology: toward an endophenotype. Clin. Psychol. Rev. 28, 1343-1354. https://doi.org/10.1016/j.cpr.2008.07.003

Parra, L.C., Spence, C.D., Gerson, A.D., Sajda, P., 2005. Recipes for the linear analysis of EEG. Neuroimage 28, 326-341. https://doi.org/10.1016/j.neuroimage.2005.05.032

Pernet, C.R., Appelhoff, S., Flandin, G., Phillips, C., Delorme, A., Oostenveld, R., 2018a. BIDS-EEG: an extension to the Brain Imaging Data Structure (BIDS) Specification for electroencephalography. PsyArXiv. December 6.

Pernet, C.R., Garrido, M., Gramfort, A., Maurits, N., Michel, C., Pang, E., Salmelin, R., Schoffelen, J.M., Valdes-Sosa, P.A., Puce, A., 2018b. Best Practices in Data Analysis and Sharing in Neuroimaging using MEEG. https://doi.org/10.31219/osf.io/a8dhx

Pfefferbaum, A., Wenegrat, B.G., Ford, J.M., Roth, W.T., Kopell, B.S., 1984. Clinical application of the P3 component of event-related potentials. II. Dementia, depression and schizophrenia. Electroencephalogr. Clin. Neurophysiol. 59, 104-124. https://doi.org/10.1016/0168-5597(84)90027-3

Schumann, G., Loth, E., Banaschewski, T., Barbot, A., Barker, G., Büchel, C., Conrod, P.J., Dalley, J.W., Flor, H., Gallinat, J., Garavan, H., Heinz, A., Itterman, B., Lathrop, M., Mallik, C., Mann, K., Martinot, J.-L., Paus, T., Poline, J.-B., Robbins, T.W., Rietschel, M., Reed, L., Smolka, M., Spanagel, R., Speiser, C., Stephens, D.N., Ströhle, A., Struve, M., IMAGEN consortium, 2010. The IMAGEN study: reinforcement-related behaviour in normal brain function and psychopathology. Mol. Psychiatry 15, 1128-1139. https://doi.org/10.1038/mp.2010.4

Simmons, J.P., Nelson, L.D., Simonsohn, U., 2011. False-positive psychology: undisclosed flexibility in data collection and analysis allows presenting anything as significant. Psychol. Sci. 22, 1359-1366. https://doi.org/10.1177/0956797611417632

Sudlow, C., Gallacher, J., Allen, N., Beral, V., Burton, P., Danesh, J., Downey, P., Elliott, P., Green, J., Landray, M., Liu, B., Matthews, P., Ong, G., Pell, J., Silman, A., Young, A., Sprosen, T., Peakman, T., Collins, R., 2015. UK biobank: an open access resource for identifying the causes of a wide range of complex diseases of middle and old age. PLoS Med. 12, e1001779. https://doi.org/10.1371/journal.pmed.1001779

Thibodeau, R., Jorgensen, R.S., Kim, S., 2006. Depression, anxiety, and resting frontal EEG asymmetry: a meta-analytic review. J. Abnorm. Psychol. 115, 715-729. https://doi.org/10.1037/0021-843X.115.4.715

Wang, J., Barstein, J., Ethridge, L.E., Mosconi, M.W., Takarae, Y., Sweeney, J.A., 2013. Resting state EEG abnormalities in autism spectrum disorders. J. Neurodev. Disord. 5, 24. https://doi.org/10.1186/1866-1955-5-24

Winkler, I., Brandl, S., Horn, F., Waldburger, E., Allefeld, C., Tangermann, M., 2014. Robust artifactual independent component classification for BCI practitioners. J. Neural Eng. 11, 035013. https://doi.org/10.1088/1741-2560/11/3/035013

Winkler, I., Haufe, S., Tangermann, M., 2011. Automatic classification of artifactual ICA-components for artifact removal in EEG signals. Behav. Brain Funct. 7, 30. https://doi.org/10.1186/1744-9081-7-30

Woo, C.-W., Chang, L.J., Lindquist, M.A., Wager, T.D., 2017. Building better biomarkers: brain models in translational neuroimaging. Nat. Neurosci. 20, 365-377. https://doi.org/10.1038/nn.4478 


\section{Appendix A. Figure 1}

bioRxiv preprint first posted online Nov. 4, 2018; doi: http://dx.doi.org/10.1101/460469. The copyright holder for this preprint (which A was not peer-reviewed) is the author/funder who has grantod piopxiv a licanse to display the preprint in perpetuity.

$\mathbf{F z}$

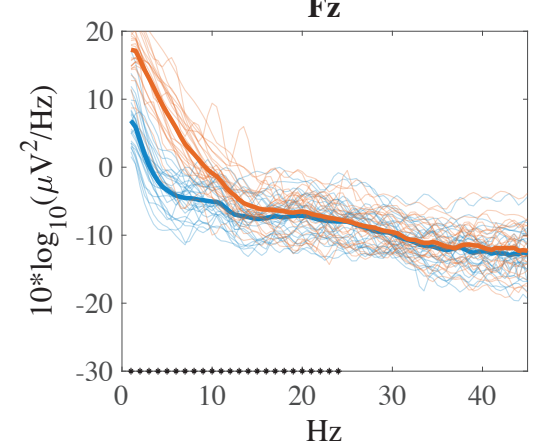

B

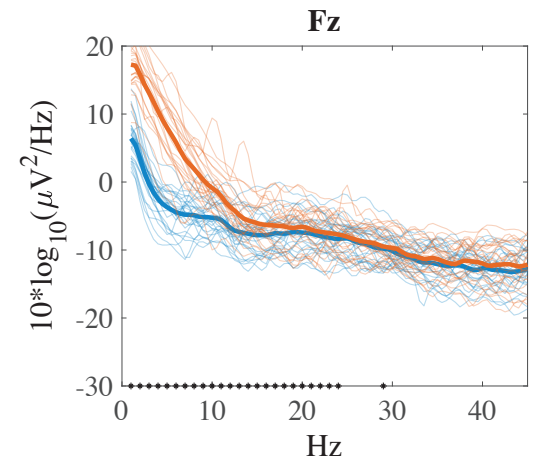

$\mathrm{C}$

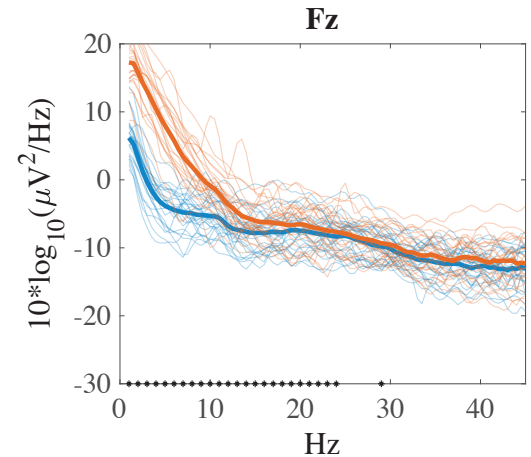

$\mathrm{D}$

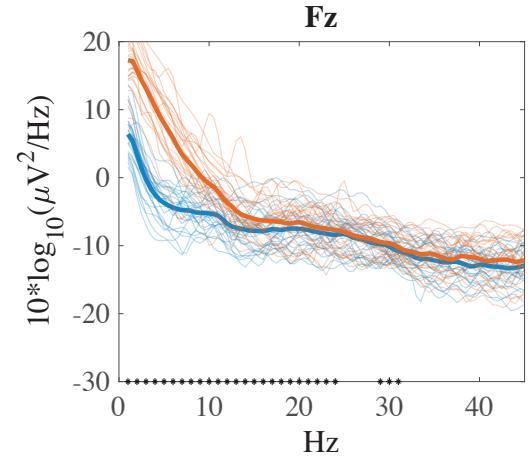

$\mathrm{Cz}$

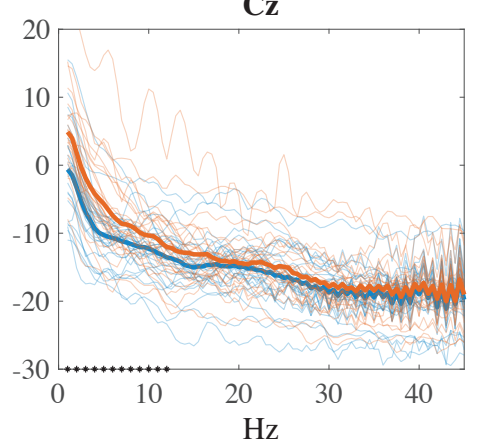

$1 \mathrm{~Hz}+\mathrm{PREP}$

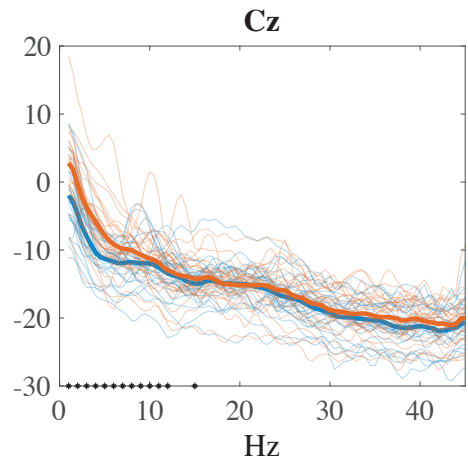

$1 \mathrm{~Hz}+$ Clean rawdata()

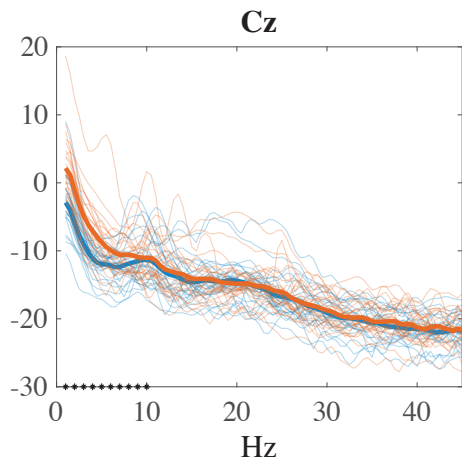

$1 \mathrm{~Hz}+\mathrm{PREP}+$ Clean rawdata()

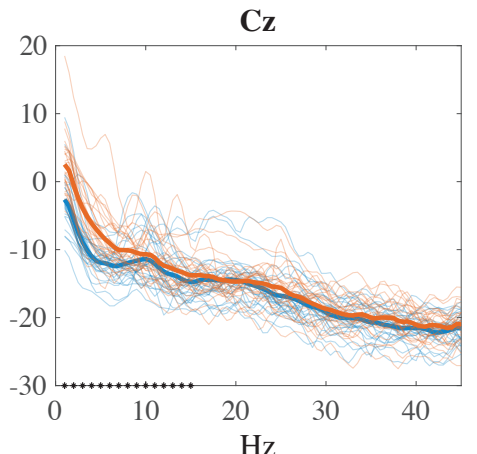

$\mathrm{Oz}$
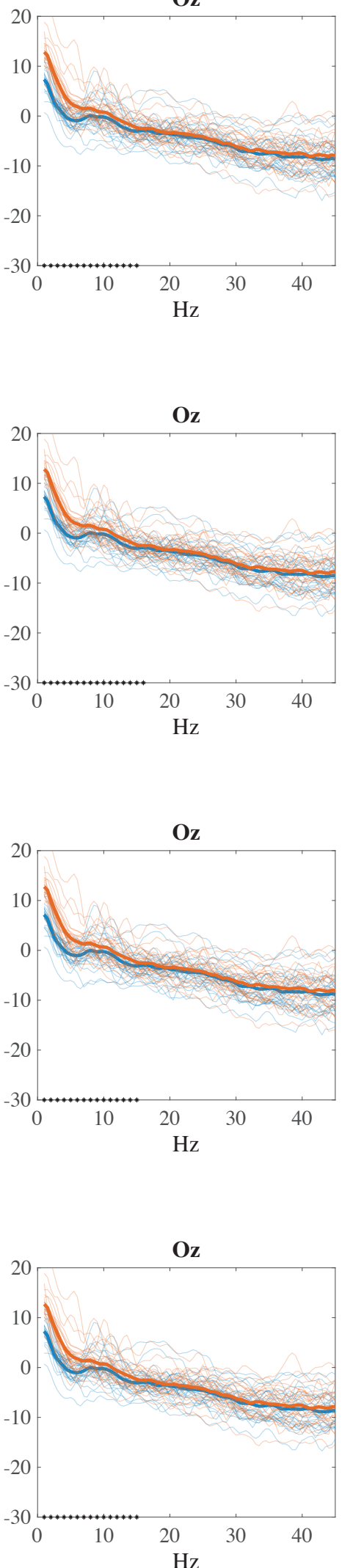
bioRxiv preprint first posted online Nov. 4, 2018; doi: http://dx.doi.org/10.1101/460469. The copyright holder for this preprint (which $\mathrm{E}$ was not peer-reviewed) is the author/funder, who has grantegiopiva ligense to display the preprint in perpetuity.

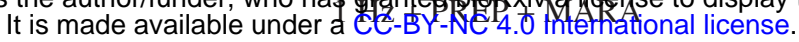
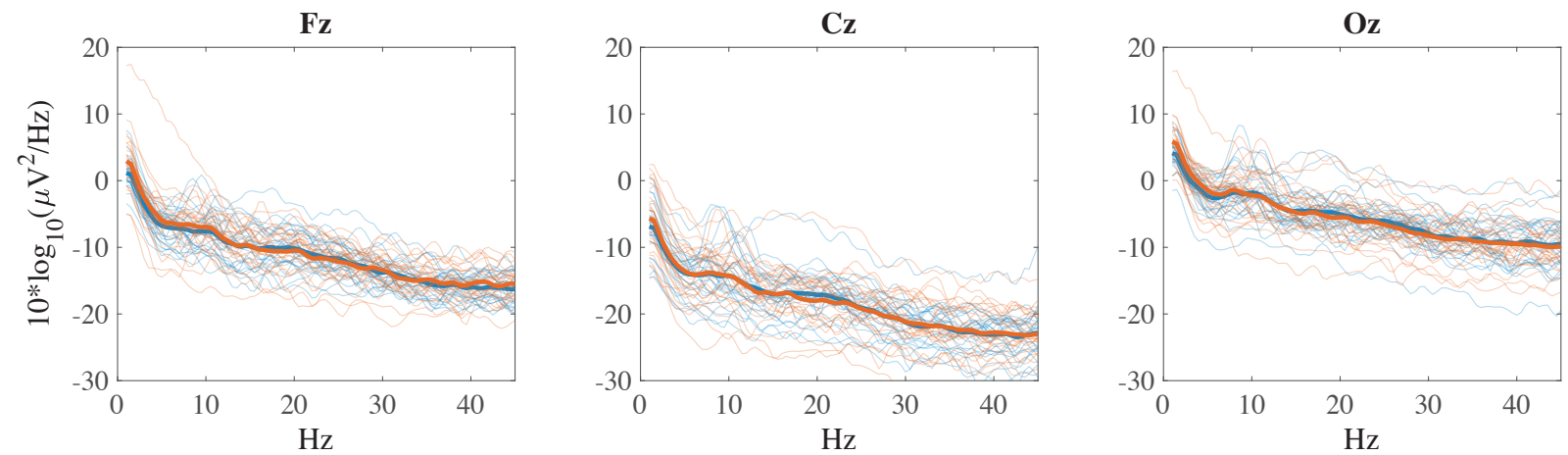

$\mathrm{F}$

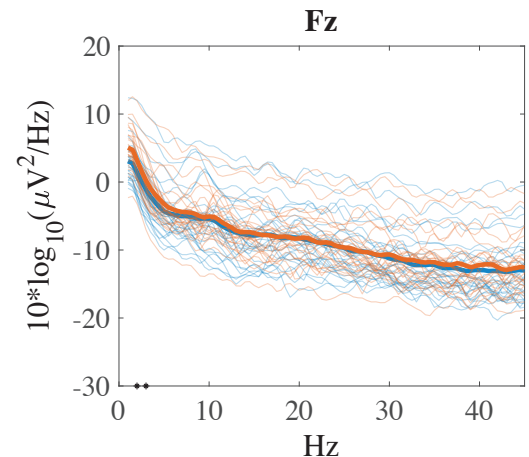

G

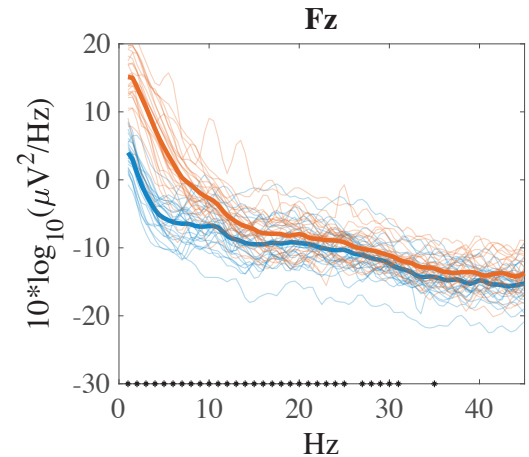

$\mathrm{H}$

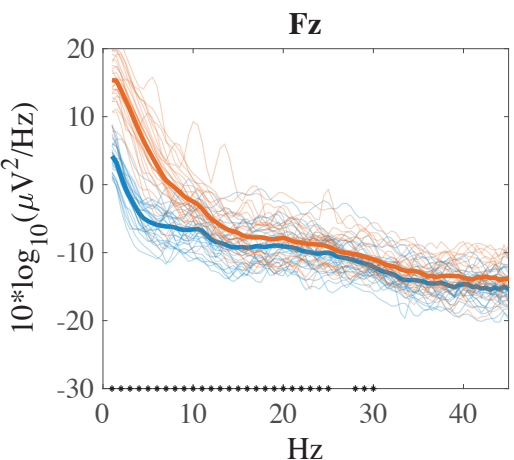

$1 \mathrm{~Hz}+$ Clean rawdata ()$+$ MARA

$\mathrm{Cz}$

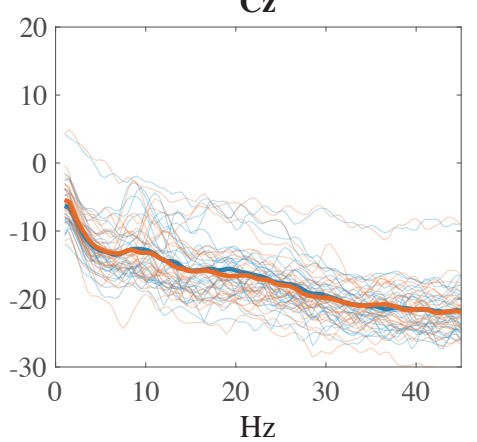

$1 \mathrm{~Hz}+\mathrm{PREP}+\mathrm{rPCA}$

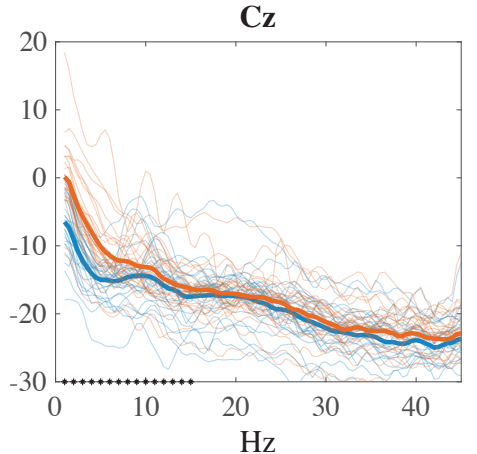

$1 \mathrm{~Hz}+$ Clean rawdata ()$+$ rPCA

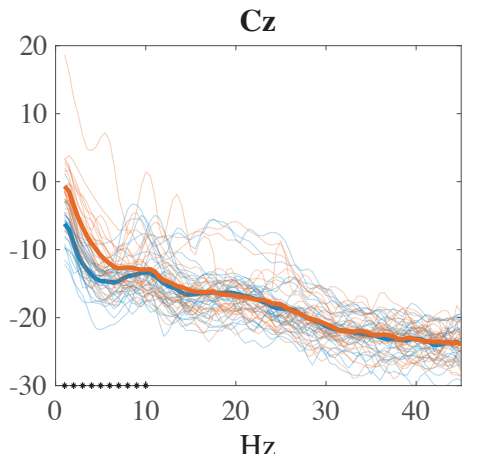

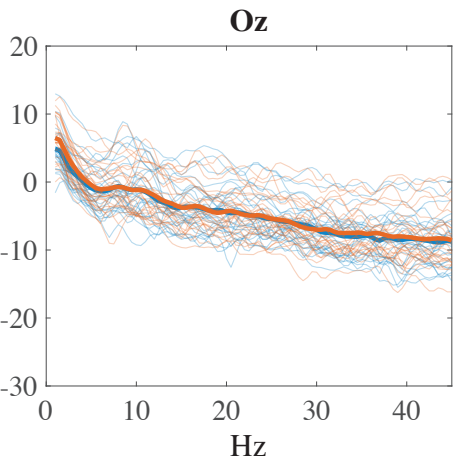
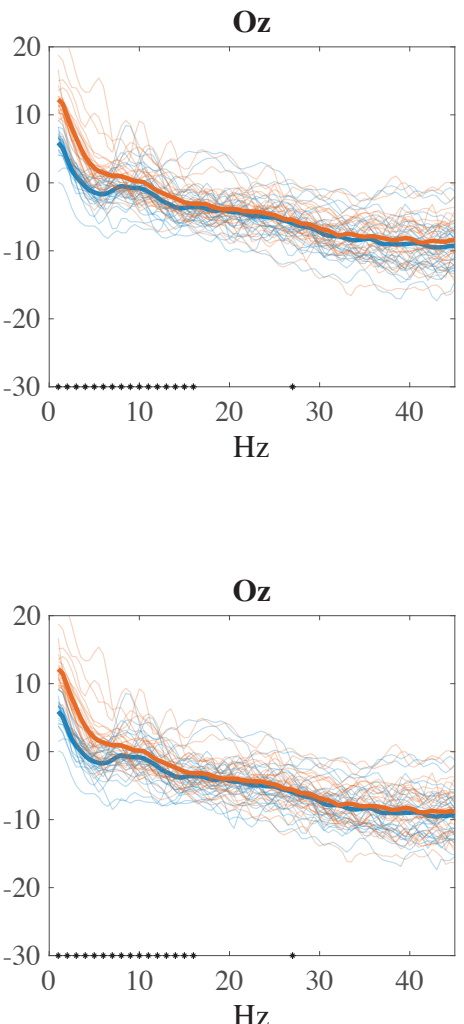
bioRxiv preprint first posted online Nov. 4, 2018; doi: http://dx.doi.org/10.1101/460469. The copyright holder for this preprint (which

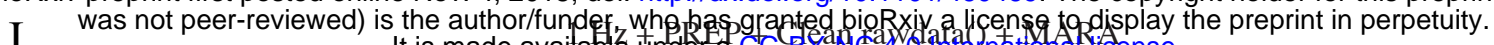

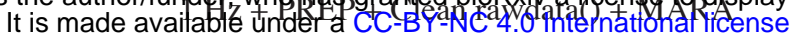
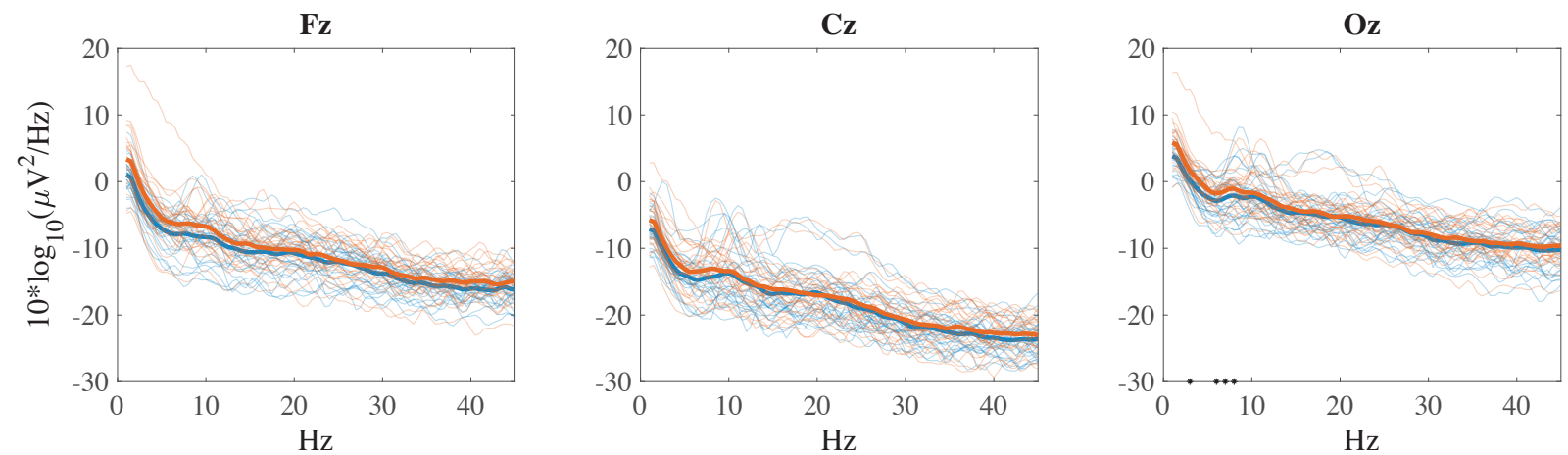

$\mathrm{J}$

$1 \mathrm{~Hz}+\mathrm{PREP}+$ Clean rawdata ()$+\mathrm{rPCA}$
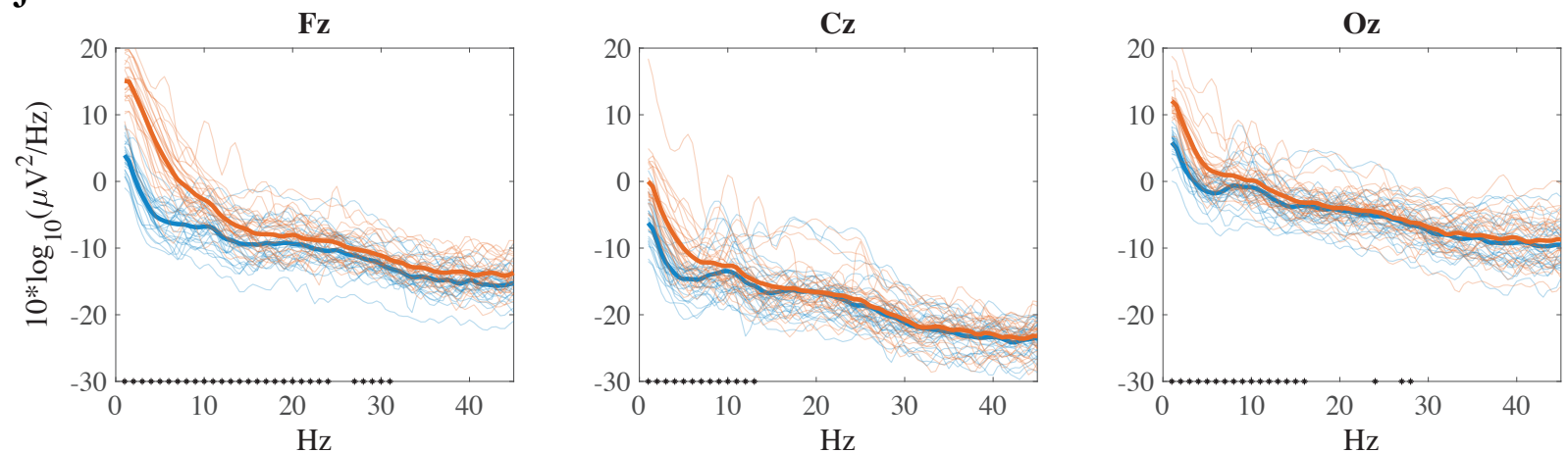

$\mathrm{K}$

$$
1 \mathrm{~Hz}+\mathrm{PREP}+\mathrm{EOGr}
$$
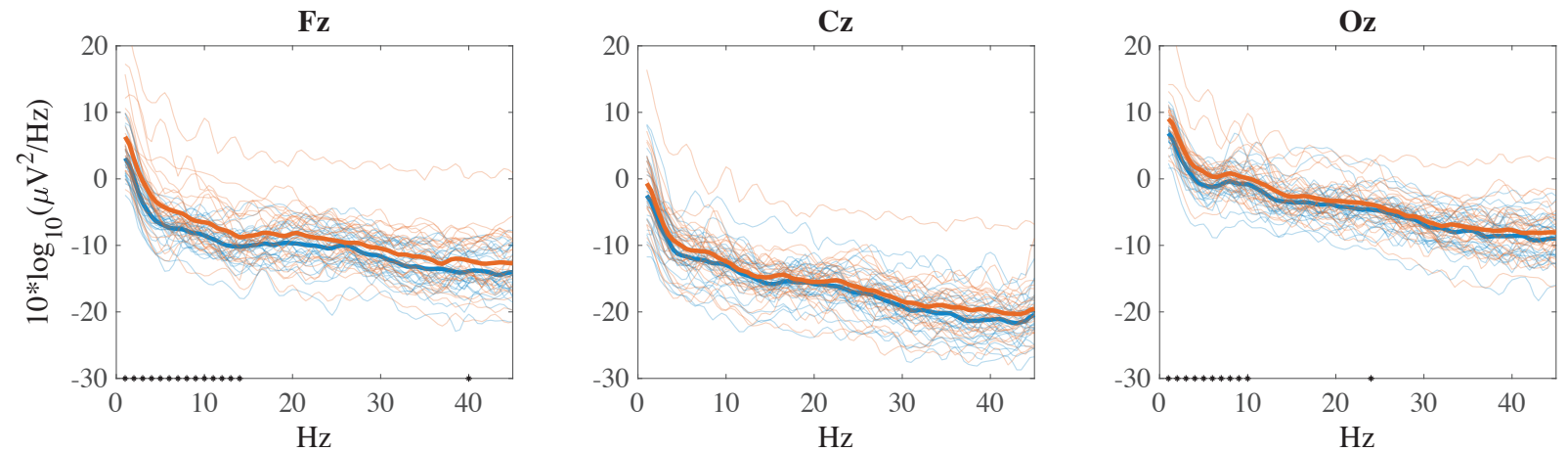

$\mathrm{L}$

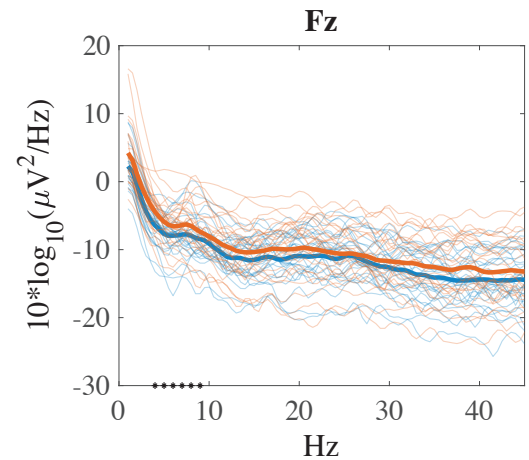

$1 \mathrm{~Hz}+$ Clean rawdata ()$+$ EOGr

$\mathrm{Cz}$

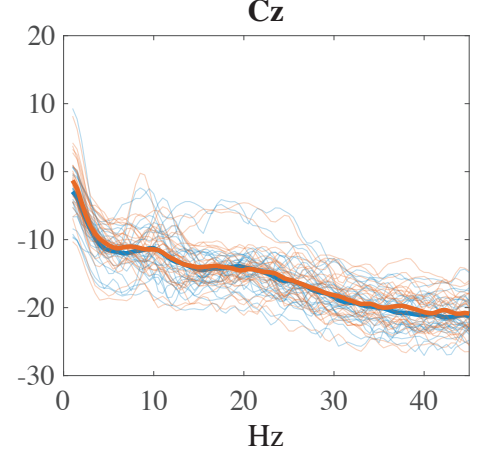

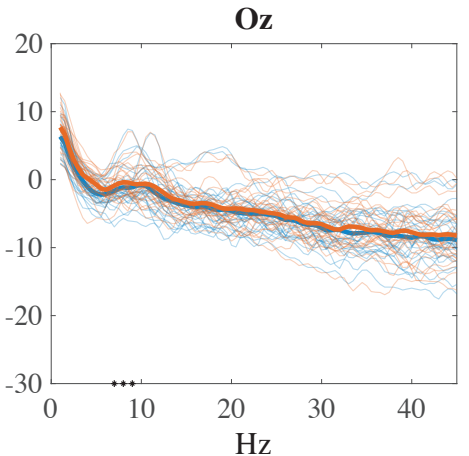


bioRxiv preprint first posted online Nov. 4, 2018; doi: http://dx.doi.org/10.1101/460469. The copyright holder for this preprint (which $\mathrm{M}$ was not peer-reviewed) is the author/funder who be

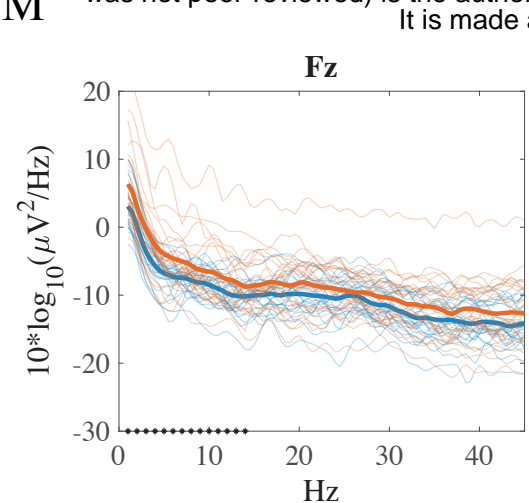

$\mathrm{Cz}$

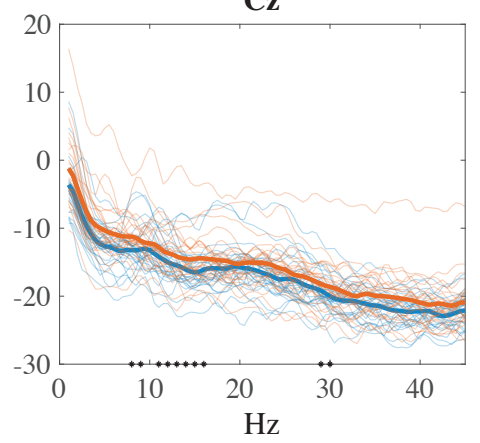

$1 \mathrm{~Hz}+\mathrm{PREP}+\mathrm{MARA}+\mathrm{EOGr}$

$\mathrm{Cz}$

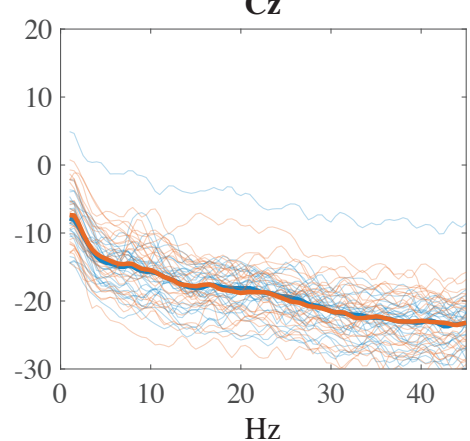

$\mathrm{Oz}$

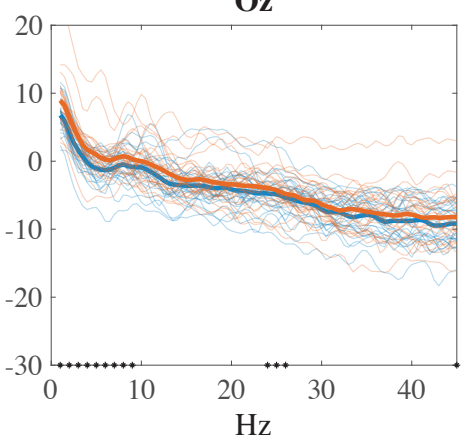

N

$\mathbf{F z}$

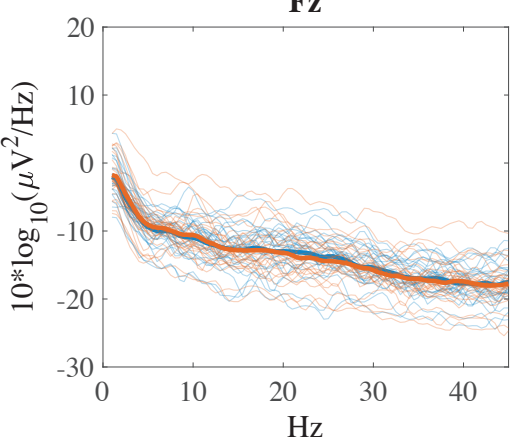

$\mathrm{O}$

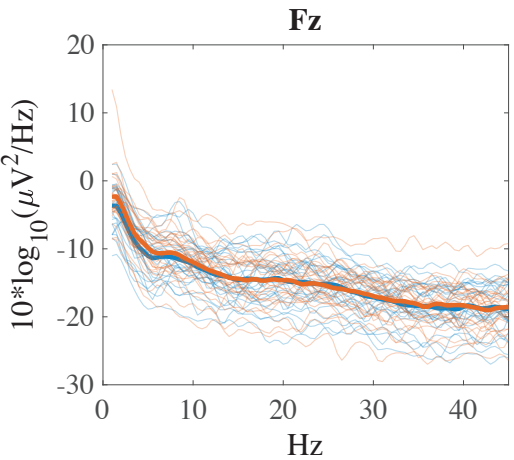

$1 \mathrm{~Hz}+$ Clean rawdata ()$+$ MARA + EOGr
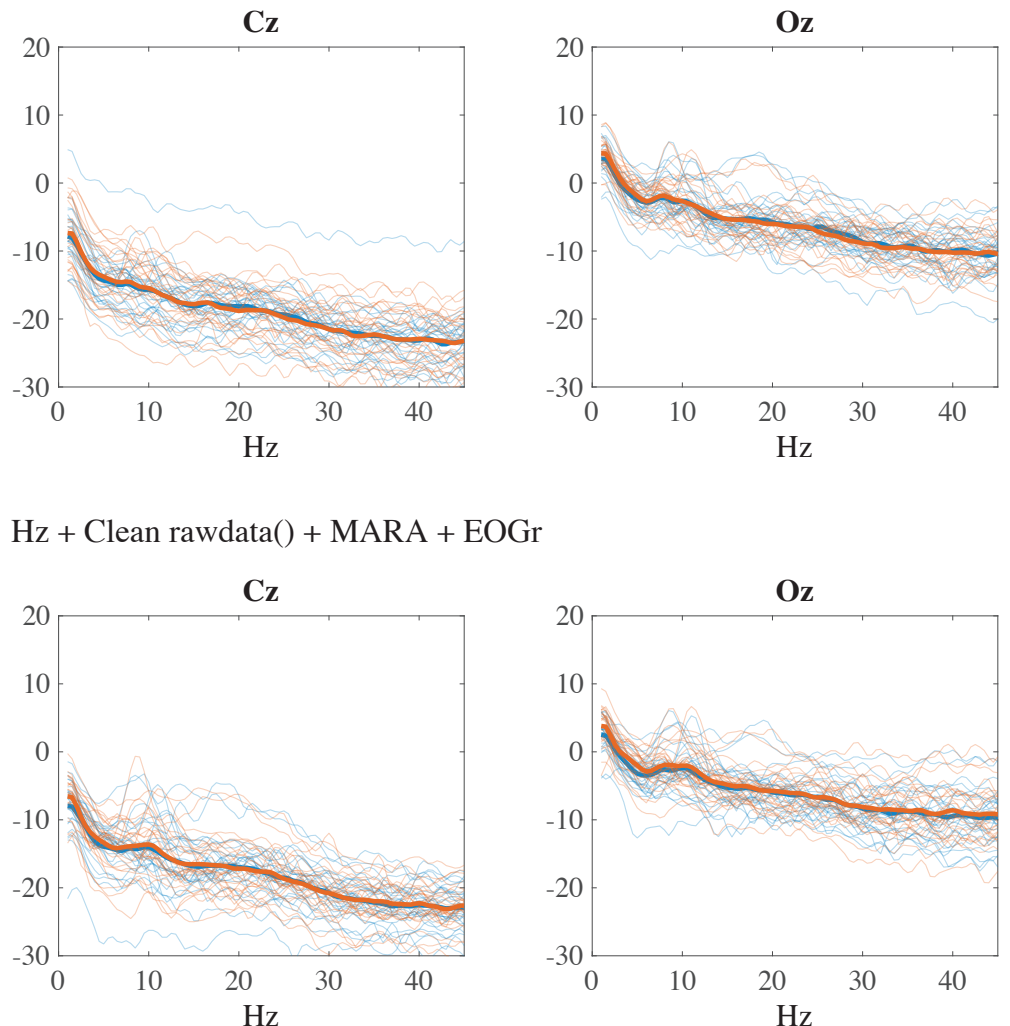

$\mathrm{P}$

$1 \mathrm{~Hz}+\mathrm{PREP}+$ Clean rawdata() + MARA + EOGr
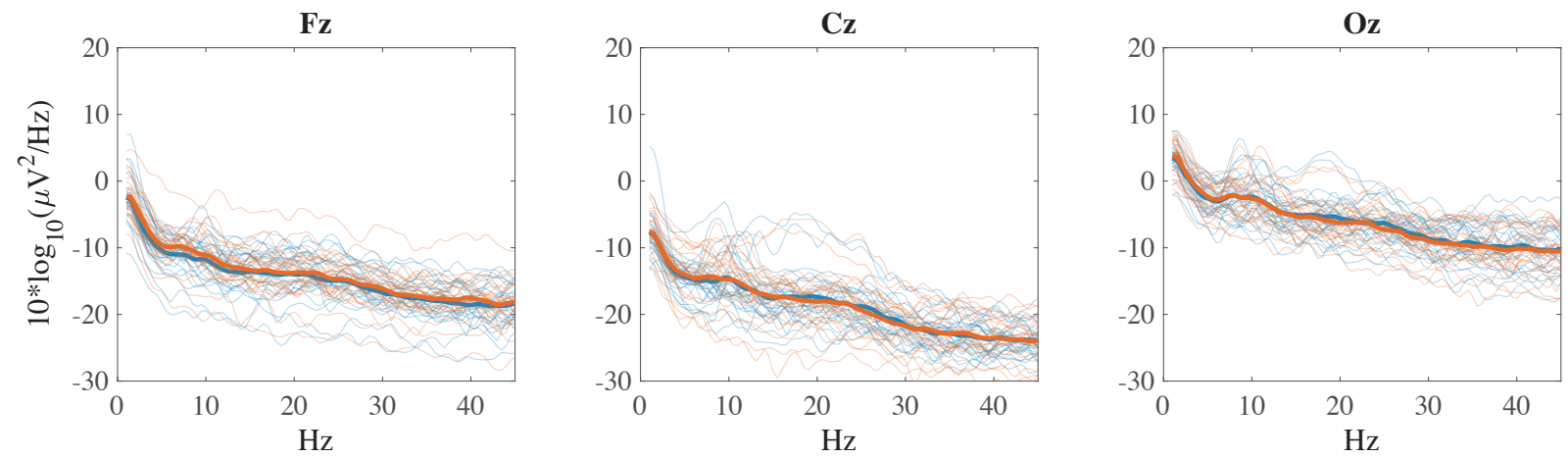
bioRxiv preprint first posted online Nov. 4, 2018; doi: http://dx.doi.org/10.1101/460469. The copyright holder for this preprint (which $\mathrm{Q}$

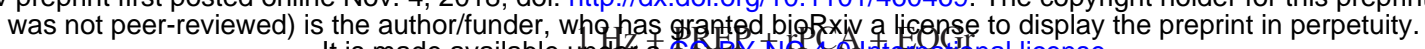

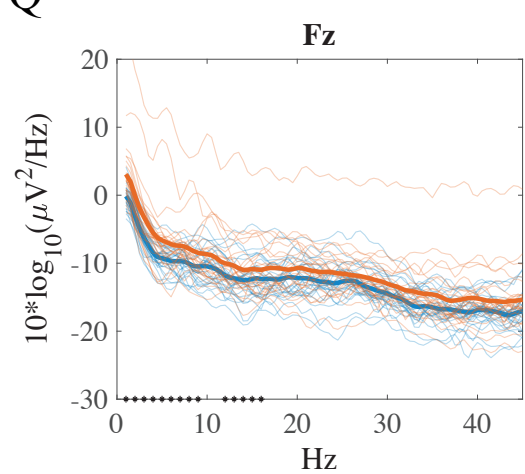

$\mathrm{Cz}$

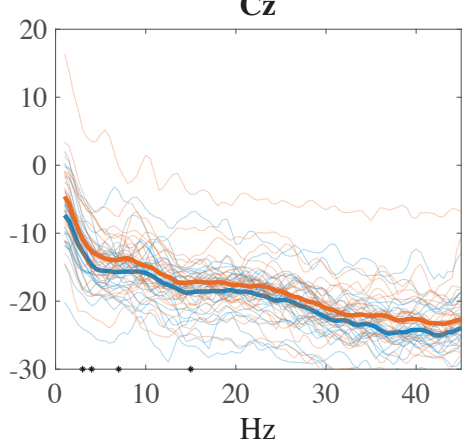

$\mathrm{Oz}$

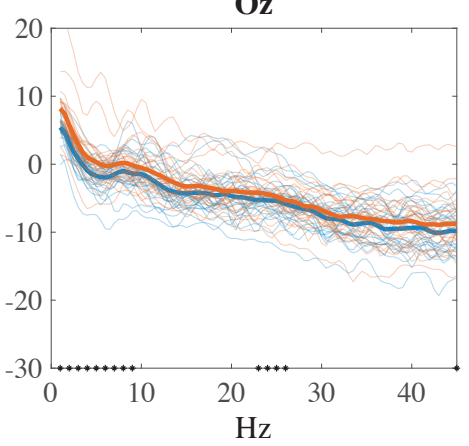

$\mathrm{R}$

$1 \mathrm{~Hz}+$ Clean rawdata ()$+\mathrm{rPCA}+\mathrm{EOGr}$

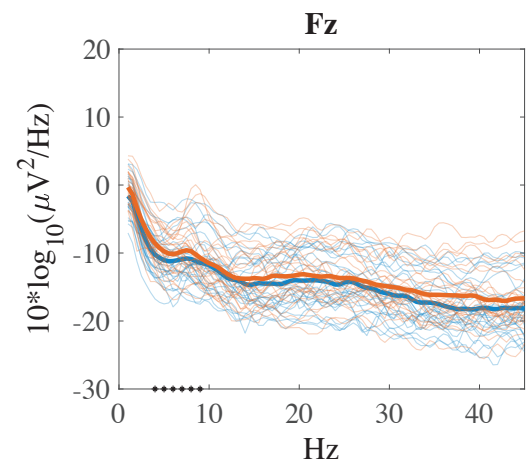

$\mathrm{Cz}$

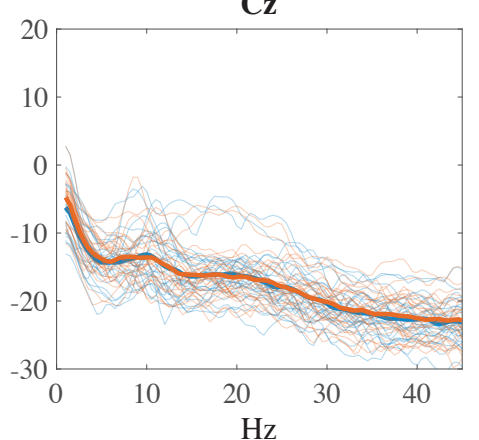

$\mathrm{Oz}$

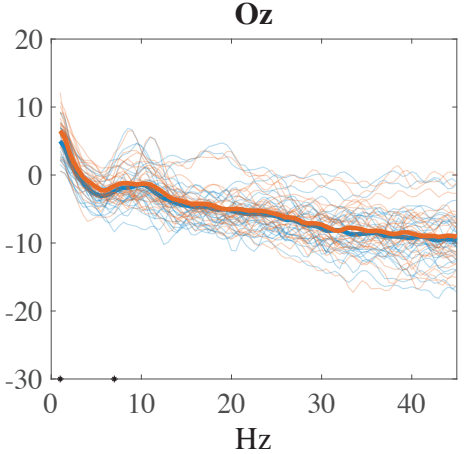

$\mathrm{S}$

$1 \mathrm{~Hz}+\mathrm{PREP}+$ Clean rawdata ()$+\mathrm{rPCA}+\mathrm{EOGr}$
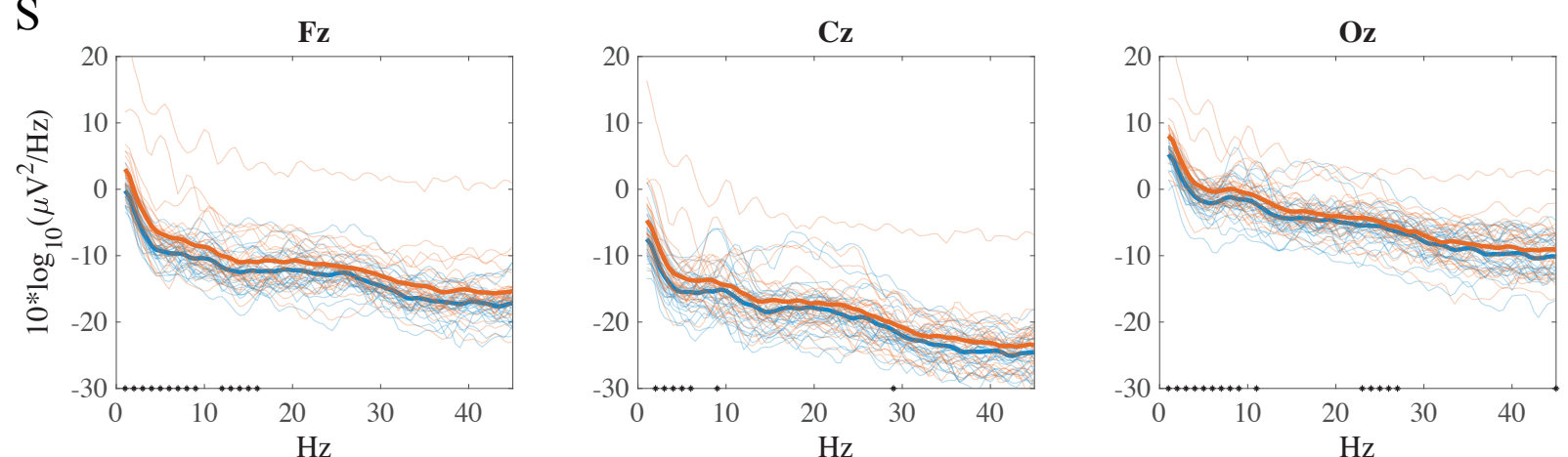